\title{
Climate Sensitivity of the Community Climate System Model Version 4
}

\author{
C. M. Bitz ${ }^{1}$, K.M. Shell ${ }^{2}$, P.R. Gent ${ }^{3}$, D. Bailey ${ }^{3}$, G. Danabasoglu ${ }^{3}$, K.C. \\ Armour ${ }^{1}$, M. M. Holland ${ }^{3}$, J.T. Kiehl ${ }^{3}$
}

\begin{abstract}
.
Equilibrium climate sensitivity of the Community Climate System Model Version 4 (CCSM4) is $3.20^{\circ} \mathrm{C}$ for $1^{\circ}$ horizontal resolution in each component. This is about a half degree Celsius higher than in the previous version (CCSM3). The transient climate sensitivity of CCSM4 at $1^{\circ}$ resolution is $1.72^{\circ} \mathrm{C}$, which is about $0.2^{\circ} \mathrm{C}$ higher than in CCSM3. These higher climate sensitivities in CCSM4 cannot be explained by the change to a preindustrial baseline climate. We use the radiative kernel technique to show that from CCSM3 to CCSM4, the global mean lapse-rate feedback declines in magnitude, and the shortwave cloud feedback increases. These two warming effects are partially canceled by cooling due to slight decreases in the global mean water-vapor feedback and longwave cloud feedback from CCSM3 to CCSM4.

A new formulation of the mixed-layer, slab ocean model in CCSM4 attempts to reproduce the SST and sea ice climatology from an integration with a full-depth ocean, and it is integrated with a dynamic sea ice model. These new features allow an isolation of the influence of ocean dynamical changes on the climate response when comparing integrations with the slab ocean and full-depth ocean. The transient climate response of the full-depth ocean version is 0.54 of the equilibrium climate sensitivity when estimated with the new slab ocean model version for both CCSM3 and CCSM4. We argue the ratio is the same in both versions because they have about the same zonal mean pattern of change in ocean surface heat flux, which broadly resembles the zonal mean pattern of net feedback strength.
\end{abstract}

\section{Introduction}

Equilibrium climate sensitivity (ECS) is an often used metric to evaluate the climate response to a perturbation in the radiative forcing. It is specifically defined as the equilibrium change in global mean surface air temperature that results from doubling the concentration of carbon dioxide $\left(\mathrm{CO}_{2}\right)$ in the atmosphere (IPCC, 1990). In this study we investigate how the new Community Climate System Model Version 4 (CCSM4) responds to doubling $\mathrm{CO}_{2}$ compared to the previous version (CCSM3) by evaluating ECS and the regional climate response when the models are integrated with a slab ocean model. We also examine the transient response in multi-century integrations of idealized $\mathrm{CO}_{2}$ doubling experiments of CCSM3 and CCSM4 with a full-depth, ocean general circulation model (OGCM).

The CCSM3 was used extensively for climate studies

\footnotetext{
${ }^{1}$ Atmospheric Sciences, University of Washington

${ }^{2}$ College of Oceanic and Atmospheric Sciences, Oregon State University

${ }^{3}$ National Center for Atmospheric Research
}

documented in the Intergovernmental Panel on Climate Change (IPCC) Fourth Assessment Report (AR4) [e.g., Randall et al., 2007] and, in subsequent years, by the wider community. By comparing climate sensitivity in CCSM3 and CCSM4 for standard idealized $\mathrm{CO}_{2}$ doubling experiments, we gain a deeper understanding of the new model by referencing it to other models we know well. We also aim to learn how the new model will compare to the larger body of climate models that will be part of IPCC AR5.

An estimate of the ECS in climate models with an OGCM requires very long simulations (thousands of years) to achieve a steady state. Climate models are rarely run long enough, and instead the ECS is usually approximated from a climate model with a mixedlayer ocean model, which we call a slab-ocean model (SOM), with prescribed, annually-periodic ocean heat transport.

Typically the SOM is designed to reproduce observed SST and sea ice cover [e.g., McFarlane et al., 1992; Kiehl et al., 2006; Knutson, 2009; Schmidt et al., 2006]. However, reproducing observations rather than the mean 
state of the climate model with an OGCM has two undesirable side effects for estimating ECS as well as the regional climate response to doubling $\mathrm{CO}_{2}$. The first is that the mean climate may differ substantially for the same climate model with SOM versus OGCM. Boer and Yu [2003a] and Boer and Yu [2003c] show that the mean climate influences the pattern of temperature response and effective climate sensitivity (an estimate of ECS from transient integrations, see section 4), and hence the equilibrium response to doubling $\mathrm{CO}_{2}$ may differ for the same climate model with a SOM versus OGCM. The second is that it is difficult to simulate accurately the sea-ice covered seas because observations of the sea-ice mass balance are inadequate to construct needed input to the SOM. CCSM3's standard SOM has motionless sea ice to simplify the problem. Even so, the sea-ice thickness pattern can be unlike nature, and yet the base-state thickness is known to significantly affect sea ice response in climate models [Holland and Bitz, 2003; Bitz and Roe, 2004; Bitz, 2008].

The slab-ocean model in the CCSM4 has been revised substantially to remedy both of these problems, and now it reproduces well the SST and sea ice of the CCSM4 with the full OGCM and uses the full physics of the sea ice component model. (In fact, the same sea ice physics must be used with the SOM as in the OGCM.) The new SOM permits a fruitful comparison of the climate model run with SOM and OGCM as a way to evaluate the role of ocean dynamics, as has already been done by Bitz et al. [2006] and McCusker et al. [2011] with the new SOM implemented in CCSM3. Several other climate models have had full sea ice physics in their SOMs before CCSM4 [e.g., Knutson, 2009; Schmidt et al., 2006].

In this study we evaluate the dependence of ECS on several new features in the CCSM4 atmosphere and land component models as well as the SOM formulation. The ECS in CCSM4 is defined relative to 1850 level $\mathrm{CO}_{2}$, rather than the present day level as was done in CCSM3. We explore the consequences of this change in baseline $\mathrm{CO}_{2}$ as well. Spatial patterns of a variety of climate variables along with radiative kernel feedback analysis are used to investigate model differences. For both CCSM3 and CCSM4, we compare the transient climate response in the models with an OGCM to the ECS.

\section{Model Descriptions}

The CCSM3 and CCSM4 are well described by Collins et al. [2006] and Gent et al. [2011], respectively, so we only briefly summarize the new aspects of CCSM4 that might affect climate sensitivity in section 2.1. Because we find the SOM formulation has a considerable effect on ECS, we go into greater depth about the SOM in section 2.2. Experimental details and a brief description of the surface climate in the SOM models are given in sections 2.3 and 2.4 , respectively.

Table 1 summarizes the configurations of the model that are used in this study.

Table 1. Model configurations used in this study.

\begin{tabular}{ll}
\hline Configuration & Description \\
\hline \hline CCSM3-OLDSOM & $\begin{array}{l}\text { Complete atmosphere and land } \\
\text { components, thermodynamic- } \\
\text { only sea ice and slab ocean as } \\
\text { in Kiehl et al. [2006] } \\
\text { Complete atmosphere, land, } \\
\text { and sea ice components, and } \\
\text { slab ocean as in section 2.2 } \\
\text { Complete atmosphere, land, } \\
\text { and sea ice components, and } \\
\text { slab ocean as in section 2.2 } \\
\text { Complete atmosphere, land, } \\
\text { sea ice, and ocean components } \\
\text { Complete atmosphere, land, } \\
\text { sea ice, and ocean components }\end{array}$ \\
\hline
\end{tabular}

\subsection{Model changes relevant to climate sensitivity}

The CCSM4 is made up of the Community Atmosphere Model version 4 (CAM4), the Community Land Model version 4 (CLM4), the sea ice component version 4 (CICE4), and the Parallel Ocean Program version 2 (POP2).

The atmosphere model has a newly revised version of the Zhang and McFarlane [1995] deep convection scheme that allows an ascending convective parcel to mix with its environment, a so-called dilute mixing assumption [Neale et al., 2008]. CAM4 now includes the effects of deep convection in the momentum equation, which has been shown to reduce many of the biases in the surface winds, tropical convection, and the Hadley circulation in CAM3 [Richter and Rasch, 2008]. The low cloud fraction in cold, dry conditions has been reduced by the inclusion of a new parameterization called "freeze-dry" [Vavrus and Waliser, 2008]. These and other changes to CAM4 are documented in Neale et al. [2011].

The changes in CLM4 that are most relevant to climate sensitivity are the addition of a carbon-nitrogen (CN) cycling and modifications to assumptions about how snow covers vegetation. These and other changes to CLM4 are documented in Lawrence et al. [2011]. The $\mathrm{CN}$ cycling involves a prognostic calculation of carbon and nitrogen in vegetative and soil processes, with timevarying leaf area and vegetation height. The CN cycling is a slow process compared to most processes that have traditionally been included in estimates of ECS [e.g., see Lunt et al., 2010]. Both CN cycling and the new snow burial parameterizations affect surface albedo and are therefore candidates to affect climate sensitivity. How- 
ever, we tested the sensitivity to $\mathrm{CN}$ cycling in isolation and found it had a negligible effect on ECS. We do not present these results below because the tests used a predecessor to the $Q_{\mathrm{flx}}$ used in all the other CCSM4 integrations described in this paper.

The primary change to CICE4 is the new multiplescattering radiative transfer scheme of Briegleb and Light [2007]. This scheme requires a melt pond fractional coverage, which has been parameterized as outlined in Holland et al. [2011].

There are numerous changes to POP2 that affect results we discuss in section 4 and, in so far as they alter the mean state SST, integrations with the SOM. The vertical resolution of the ocean increased from 40 to 60 levels from CCSM3 to CCSM4, which improves the thermocline structure and the SST. In CCSM4, the Labrador Sea convection site is in better agreement with observations than in CCSM3, most likely owing to the new overflow parameterization and reduced horizontal viscosities in CCSM4. Adjustments to mesoscale and vertical mixing and the addition of a new submesocale mixing scheme all influence mixed-layer depths, surface heat fluxes, and ocean temperature change in response to climate perturbations. These and other changes to POP2 in CCSM4 are described by Danabasoglu et al. [2011].

\subsection{Changes to the Slab-Ocean Model}

A slab-ocean model treats the ocean as motionless but perfectly mixed throughout its depth. The primary challenge is to construct an ocean heat transport convergence that can be prescribed in the SOM to achieve a desirable mean climate. We refer to this heat transport convergence as a $Q_{\mathrm{flx}}$. To estimate ECS, the $Q_{\mathrm{flx}}$ should be annually periodic, and the $Q_{\mathrm{fx}}$ should not differ between integrations with different radiative forcings.

Estimating the $Q_{\mathrm{fx}}$ typically involves a special integration procedure. At least two methods have been employed in the past. One is to perform an Atmospheric Model Intercomparison (AMIP)-type experiment where the atmosphere and land components are integrated with prescribed climatologies of SST and sea ice concentration and thickness. The $Q_{\mathrm{fx}}$ is derived from the net surface fluxes, with corrections in sea-ice covered seas based on estimates of the sea ice mass budget. This technique is used in the SOM in the standard CCSM3, which we refer to as the OLDSOM, and in models from the Canadian Centre for Climate Modelling and Analysis [McFarlane et al., 1992] and NASA/Goddard Institute for Space Studies [Schmidt et al., 2006]. A second method is to run an integration with the SOM initially with zero $Q_{\mathrm{flx}}$ but with SST and sea ice concentration and thickness restored to climatology. The climatology of the restoring flux is then the $Q_{\mathrm{flx}}$ in subsequent SOM runs. This method is used by the Geophysical Fluid Dynamics Lab [Knutson, 2009] and the Hadley
Centre [Willias et al., 2000] models.

The new slab-ocean model, which we refer to as the NEWSOM, is the standard in CCSM4. The CCSM4NEWSOM is intended to reproduce the SST and sea ice of the CCSM4-OGCM, so the $Q_{\mathrm{fx}}$ is constructed from a 20-yr climatology of SST, mixed-layer depth, and fluxes from a long control of the CCSM4-OGCM at the same resolution as the CCSM4-NEWSOM, using

$$
\rho_{o} c_{p} h \frac{\partial S S T}{\partial t}=F_{\mathrm{net}}+Q_{\mathrm{flx}},
$$

where $\rho_{o}$ is the density of seawater, $c_{p}$ is the ocean heat capacity, and $h$ the mixed layer depth. The net heat flux into the ocean $F_{\text {net }}$ includes the atmosphere-to-ocean and ocean-to-sea ice basal and lateral surface fluxes and sensible (if any) and latent heat from snow falling into the ocean and sea ice growing over open ocean, and "runoff" (which includes land ice calving). The $Q_{\mathrm{flx}}$ constructed this way is so accurate that no adjustments are needed in CCSM4-NEWSOM.

The CCSM4-NEWSOM must employ the same sea ice physics of the long control run from which $F_{\text {net }}$ is derived, which is normally the full, dynamic-thermodynamic sea-ice component model of CCSM4-OGCM, with ocean drag on the sea ice computed from prescribed ocean surface currents from a CCSM4 climatology. The CCSM4NEWSOM is intended to more clossly approximate the ECS of the CCSM4-OGCM. The NEWSOM was originally implemented in CCSM3 with results shown in Holland et al. [2006], Bitz et al. [2006], and Bitz [2008], but it was not in an official release of the CCSM3. In the CCSM3-NEWSOM, the $Q_{\mathrm{fx}}$ is computed from a 20-yr climatology taken from a long control of the CCSM3-OGCM at the same resolution as the CCSM3NEWSOM.

In contrast, in the CCSM3-OLDSOM, $F_{\text {net }}$ is not well constrained in the presence of sea ice because the ocean-to-sea ice fluxes are not known to sufficient accuracy from observations to yield a reasonable sea ice mass balance. A first attempt at estimating the $Q_{\mathrm{fx}}$ gave poor results in sea-ice covered seas; therefore, additional adjustments to the $Q_{\mathrm{flx}}$ are made in the presence of sea ice. In the CCSM3-OLDSOM these are continuously computed in the slab ocean and typically amount to about $5-10 \mathrm{Wm}^{-2}$ in the ice covered seas. A further global adjustment is made to the $Q_{\mathrm{fx}}$ to maintain zero adjustments on the global mean, which essentially redirects heat from the tropics to the poles.

Because the sea-ice coverage decreases in a double $\mathrm{CO}_{2}$ scenario, these continual, or "on-the-fly" adjustments, redirect less heat from the tropics to the poles, which amounts to an additional climate forcing as shown in Fig. 1 in a zonal mean. Even though the global average of this climate forcing is nearly zero, it influences climate sensitivity because climate feedbacks are not spatially uniform [see, e.g., Boer and Yu, 2003b].

Another consideration is that CCSM3-OLDSOM does 


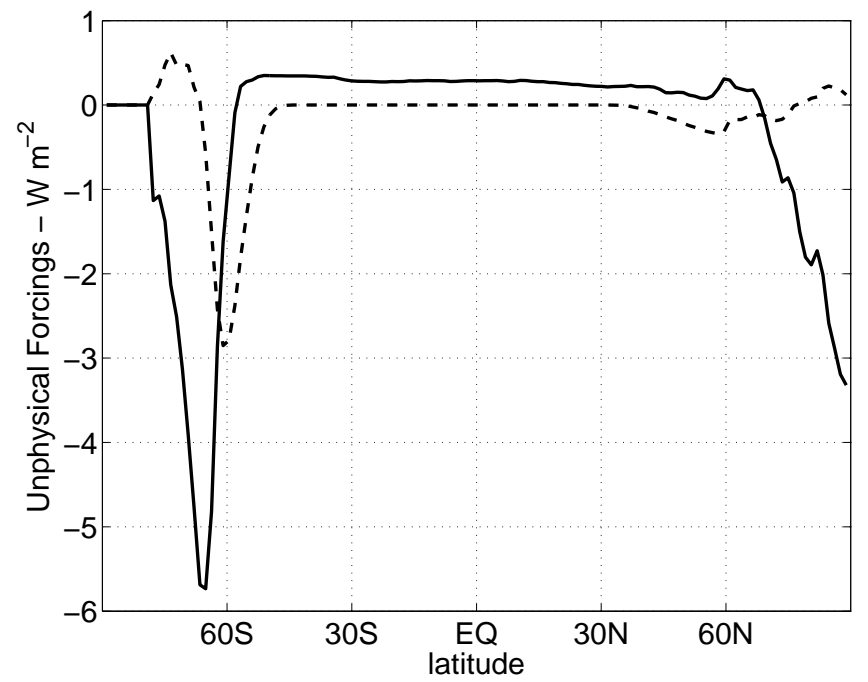

Figure 1. Zonal mean climate forcing resulting from on-the-fly adjustments to the $Q_{\mathrm{flx}}$ (solid) and from neglecting the latent heat of snow falling into the ocean (dashed) from doubling $\mathrm{CO}_{2}$ CCSM3-OLDSOM at T85.

not account for the latent heat of snow falling into the ocean. (The latent heat of snow that falls on land or sea ice is treated correctly.) In contrast, the atmosphere does gain heat when ice condensate is formed. In a climate perturbation experiment, the amount of ice condensate produced changes compared to the control, and therefore the energy imbalance is different. In the case of doubling $\mathrm{CO}_{2}$, less condensate is produced, resulting in a negative climate forcing of $0.1 \mathrm{Wm}^{-2}$ on the global mean, with much higher magnitude locally in the high latitudes of the Southern Hemisphere (see Fig. 1). The extent to which these unphysical climate forcings from on-the-fly adjustments and the latent heat of snow affect the climate and ECS in the CCSM3-OLDSOM is discussed in sections 2.4 and 3.2.

\subsection{Experimental Details}

To investigate ECS we compare integrations at $1 \mathrm{XCO}_{2}$ and $2 \mathrm{XCO}_{2}$ levels. The baseline $\mathrm{CO}_{2}$ level, however, is not the same in CCSM3 and CCSM4. The CCSM3 was developed to produce a long control integration using greenhouse gas and aerosol levels appropriate for the $1990 \mathrm{~s}$, and thus its $\mathrm{CO}_{2}$ concentration is $355 \mathrm{ppmv}$. As a result the $1 \mathrm{XCO}_{2}$ integrations with CCSM3 with a SOM also had a 1990s baseline climate. In contrast, CCSM4 was developed to produce a long control integration of the pre-industrial climate with $\mathrm{CO}_{2}$ concentration at 285ppmv, which is also used as the baseline for ECS estimates of CCSM4.

Our analysis of SOM integrations use years 31-60, unless otherwise noted. We analyze two idealized $\mathrm{CO}_{2}$ forcing scenarios with OGCMs. One has a $1 \% \mathrm{yr}^{-1}$ rate of $\mathrm{CO}_{2}$ increase applied to a branch of a long control integration. In these integrations $\mathrm{CO}_{2}$ is stabilized once it reaches twice its starting value, which occurs 70 years after $\mathrm{CO}_{2}$ ramping is initiated. In this case, we analyze 30-year means centered on the time of doubling. The second type of idealized $\mathrm{CO}_{2}$ forcing is an instantaneous doubling of $\mathrm{CO}_{2}$ in the climate model with an OGCM, for which we analyze the whole integration. These idealized scenarios with OGCMs are compared to long control integrations with annually periodic forcing only. We use 30-year averages from the long controls at a minimum of 400 years from the start of the integration.

Integrations with the CCSM4 atmosphere component at $2^{\circ}$ or finer resolution employ a finite volume dynamical core, and therefore the resolution is measured in degrees for the atmosphere and land. The lowest resolution (T31) CCSM4 runs and all integrations with CCSM3 have a spectral dynamical core in the atmosphere, and the land model has the same grid as the atmosphere physics. The ocean and sea ice resolution is nominally $1^{\circ}$ when combined with $1^{\circ}, 2^{\circ}$, T42, or T85 atmospheric resolutions and nominally $3^{\circ}$ when combined with T31 atmospheric resolution. For simplicity we note just the resolution of the atmosphere in our presentation.

We assume the radiative forcing from doubling $\mathrm{CO}_{2}$ is the same in both models and equal to $3.5 \mathrm{Wm}^{-2}$ globally averaged, using an estimate from Kay et al. [2011] of the instantaneous tropopause radiative flux change from doubling $\mathrm{CO}_{2}$ with stratospheric temperatures adjusted to their new thermal equilibrium for CCSM4. Using the same estimate for CCSM3 is partly justifiable given that the radiation code is the same. However, there is an unknown influence from differences in the mean climate state, which we effectively ignore. The estimate of global mean radiative forcing is only a factor in calculating net feedback (see section 3.1) and effective climate sensitivity (see section 4 ).

\subsection{Surface climate in the slab-ocean models}

Here we evaluate the influence of the slab-ocean formulation on the surface climatology of the $1 \mathrm{XCO}_{2}$ climate. The OLDSOM has not been implemented in CCSM4; therefore, we discuss runs with OLDSOM and NEWSOM in the CCSM3 only.

Both SOMs reproduce the SST and sea ice extent that they are intended to reproduce. Figure 2 shows an example of the SST biases for CCSM3-NEWSOM. Though statistically significant in most regions, the SST biases are typically less than $0.15^{\circ} \mathrm{C}$. However, near the sea ice edge, while the CCSM3-NEWSOM biases remain under $0.65^{\circ} \mathrm{C}$, in CCSM3-OLDSOM biases reach $2^{\circ} \mathrm{C}$ (not shown). Arctic sea ice thickness in CCSM3OLDSOM does not agree well with the limited observations that are available (see Fig. $3 \mathrm{a}$ and b), even when accounting for the difference in time period of model and observation averages. It is much too thick in the central Arctic despite the on-the-fly corrections 


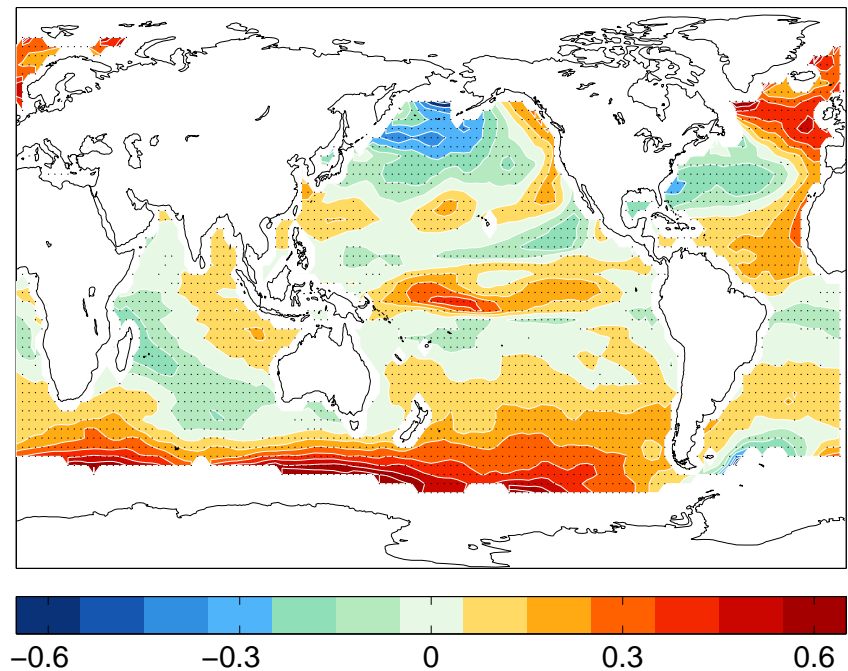

Figure 2. Sea surface temperature in CCSM3NEWSOM T42 integration (average of 125 years) minus the climotological SST from CCSM3-OGCM (the target) used to construct the $Q_{\mathrm{flx}}$ in ${ }^{\circ} \mathrm{C}$. Dots show grid cells where the SST biases are significantly different from the target, using a 95\% (two-sided) confidence interval for a 125 year run taking account of autocorrelation in the estimate of degrees of freedom in the Student's T distribution.

to the $Q_{\mathrm{flx}}$. Observations are lacking in the Antarctic for comparison, but the overall pattern in the CCSM3OLDSOM is probably reasonable (not shown). In contrast, the CCSM3-NEWSOM sea ice thicknesses (e.g., Fig. 3c) agree within a half meter of their intended targets (sea ice thicknesses from CCSM3-OGCM, e.g., Figs. 3d) in both hemispheres, except near the Antarctic continent, where the CCSM3-NEWSOM sea ice tends to be thicker than the CCSM3-OGCM sea ice by about a meter (not shown).

\section{Climate Sensitivity and Feedback Analysis at Equilibrium}

The ECS of the CCSM4-NEWSOM is $\Delta T_{e q}=2.93^{\circ} \mathrm{C}$ at $\mathrm{T} 31$ resolution, $3.13^{\circ} \mathrm{C}$ at $2^{\circ}$ resolution, and $3.20^{\circ} \mathrm{C}$ at $1^{\circ}$ resolution. The ECS of the CCSM4-NEWSOM is higher than that of CCSM3-OLDSOM by about $0.5-$ $0.6^{\circ} \mathrm{C}$ (see table 2), when comparing integrations of comparable resolution. This is an increase of roughly 20\%. The ECS of CCSM4-NEWSOM differs from CCSM3-NEWSOM by a smaller amount, about $0.35^{\circ} \mathrm{C}$. The uncertainties of the ECS in CCSM3-NEWSOM and CCSM3-OLDSOM at T42 resolution are estimated to be $0.07^{\circ} \mathrm{C}$ (see footnote of table 2 ), and we shall assume this is a good approximation for all of our integrations. Given this assumption, ECS is significantly higher in CCSM4-NEWSOM than in both CCSM3-NEWSOM and CCSM3-OLDSOM at every resolution. The res-
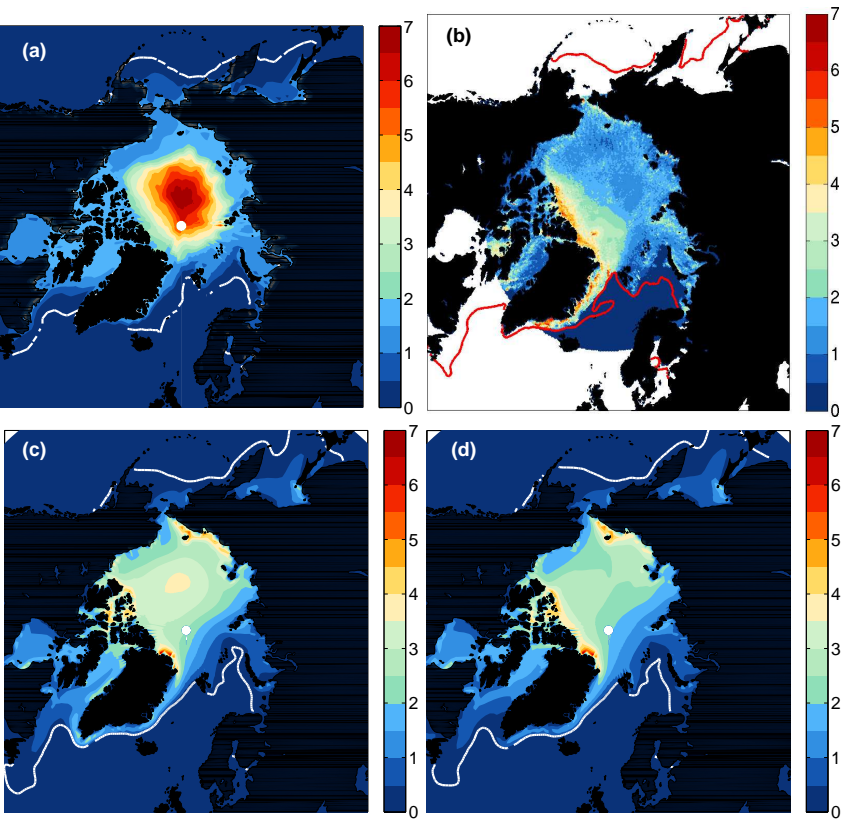

Figure 3. Arctic March sea ice thickness in meters and extent as defined by the $15 \%$ ice concentration contour in OLDSOM-CCSM3 T85 (a), observations (b), NEWSOM-CCSM3 T85 (c), and CCSM3-OGCM T85 1990s Control (d). Observations of sea ice thickness are based on ICEsat laser altimeter [Yi and Zwally, 2010] for which only 2006 and 2007 are available. Observations of ice concentration are from NASA passive microwave [Comiso, 1990]. All integrations here have 1990s level greenhouse gas forcing. It is possible that the true ice thickness was $\sim 1$ m greater in 1990 compared to what is shown here.

olution of CCSM4-NEWSOM and CCSM3-NEWSOM has no significant influence on ECS above $2^{\circ}$ or T42 resolution, while resolution has a modest effect below. This is a smaller effect than the resolution dependence of CCSM3-OLDSOM that was found by Kiehl et al. [2006].

In section 3.1 we examine the spatial structure of the equilibrium climate response along with a feedback analysis. Then in sections 3.2 and 3.3, we present results from a series of integrations that isolate particular processes to identify the aspects of the models that explain the differences in $\Delta T_{e q}$ among the integrations listed in table 2 .

\subsection{Climate Sensitivity and Feedback Analysis of CCSM3 versus CCSM4}

We now present a more detailed analysis of the causes for variations in the spatial and global equilibrium responses in our three main configurations, each at the highest resolution: CCSM3-OLDSOM T85, CCSM3NEWSOM T85, and CCSM4-NEWSOM 1 ${ }^{\circ}$. The zonalmean equilibrium surface air temperature change from 
Table 2. Equilibrium climate sensitivity for standard versions of the models.

\begin{tabular}{lcc}
\hline $\begin{array}{l}\text { Model Version } \\
\text { and SOM Method }\end{array}$ & Resolution & $\begin{array}{c}\Delta T_{\mathrm{eq}}^{a} \\
{ }^{\circ} \mathrm{C}\end{array}$ \\
\hline \hline CCSM3-OLDSOM & $\mathrm{T} 31$ & $2.40^{b}$ \\
CCSM3-OLDSOM & $\mathrm{T} 42$ & $2.53^{b} \pm 0.07^{c}$ \\
CCSM3-OLDSOM & $\mathrm{T} 85$ & 2.71 \\
CCSM3-NEWSOM & $\mathrm{T} 31$ & 2.47 \\
CCSM3-NEWSOM & $\mathrm{T} 42$ & $2.80 \pm 0.07^{c}$ \\
CCSM3-NEWSOM & $\mathrm{T} 85$ & 2.86 \\
CCSM4-NEWSOM & $\mathrm{T} 31$ & 2.93 \\
CCSM4-NEWSOM & $2^{\circ}$ & 3.13 \\
CCSM4-NEWSOM & $1^{\circ}$ & 3.20 \\
\hline
\end{tabular}

${ }^{a}$ The global mean in all runs is the mean of years 31 60, except in CCSM3-OLDSOM T31 and T85, it is from years $31-50$.

${ }^{b}$ These values may differ slightly from Kiehl et al. [2006] because we use longer averaging periods.

${ }^{c}$ Uncertainties are $2 \sqrt{2} \sigma$, where $\sigma$ is the standard deviation of $30 \mathrm{yr}$ intervals in 210 year long runs at $1 \mathrm{XCO}_{2}$. The $30 \mathrm{yr}$ intervals are non overlapping in years 1-210 and additionally 16-195 (for a total of 13 intervals). The potential bias from not reaching a true equilibrium by year 31 is estimated to be less than $0.01^{\circ} \mathrm{C}$ based on extending the $2 \mathrm{XCO}_{2}$ integrations to 110 years.

these integrations is shown in Fig. 4a. CCSM4NEWSOM warms more than both CCSM3-OLDSOM and CCSM3-NEWSOM at the surface at every latitude, except just at the equator. There is an unusual small local warming maximum on the equator in CCSM3OLDSOM that is comparably smaller in the CCSM3NEWSOM and does not occur at all in the CCSM4NEWSOM (see Fig.4a).

The temperature change aloft does not necessarily follow these surface air temperature and lower troposphere changes. Instead CCSM4-NEWSOM warms the least above about $300 \mathrm{hPa}$ between $30^{\circ} \mathrm{S}$ and $30^{\circ} \mathrm{N}$, as seen in vertical temperature profile averages (see Fig. 4c). CCSM3-OLDSOM generally warms the most above $700 \mathrm{hPa}$ in the $30^{\circ} \mathrm{S}-30^{\circ} \mathrm{N}$ average, even though its zonal-mean warming is the least at the surface at nearly every latitude. CCSM4-NEWSOM's decreased temperature change with height, combined with the increased temperature change in the lower troposphere, indicate a different lapse rate response for CCSM4NEWSOM in addition to the different meridional temperature gradient response, with CCSM3-NEWSOM generally having a temperature response magnitude between those of the other two configurations.

Accordingly, the upper tropospheric water vapor in CCSM4 also increases the least (see Fig. 5), especially in the tropics and subtropics. Below 500hPa, CCSM4NEWSOM tends to moisten as much or more than CCSM3-OLDSOM and CCSM3-NEWSOM, partially compensating for the decreased water vapor change
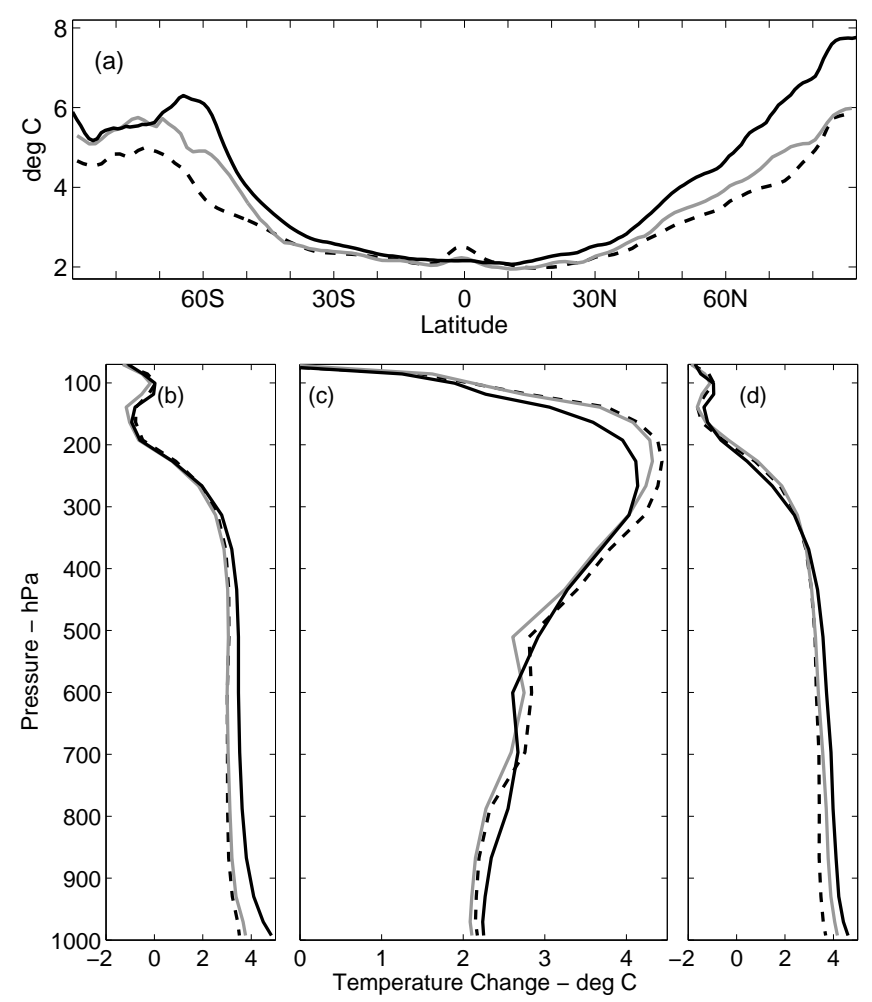

Figure 4. Change in zonal mean surface air temperature (a) and vertical temperature profiles south of $30^{\circ} \mathrm{S}$ (b), $30^{\circ} \mathrm{S}-30^{\circ} \mathrm{N}$ (c) and north of $30^{\circ} \mathrm{N}$ (d) from doubling $\mathrm{CO}_{2}$ in CCSM4-NEWSOM $1^{\circ}$ (solid black), CCSM3 NEWSOM T85 (solid grey), and CCSM3-OLDSOM T85 (dashed black).

of CCSM4-NEWSOM higher in the troposphere. The larger temperature changes combined with the smaller water vapor changes between $600-700 \mathrm{hPa}$ result in roughly a $1 \%$ reduction in relative humidity in the tropics at that level for both CCSM3-OLDSOM and CCSM3NEWSOM that does not occur in CCSM4-NEWSOM (not shown).

Middle- to high-level cloud fractions at the equator increase in CCSM3-OLDSOM (see Fig. 6a), but there is little change in CCSM3-NEWSOM and even a reduction in CCSM4-NEWSOM. These cloud changes are consistent with the local surface air temperature changes at the equator. From $10-20^{\circ} \mathrm{N}$ and $10-20^{\circ} \mathrm{S}$ the middle- to high-level cloud fractions change with opposite sign to the equatorial values, again with CCSM3OLDSOM changing the most and CCSM4-NEWSOM changing the least. We also examined the cloud fraction changes in two-dimensional maps and in the three runs shown in Fig 6 and in some of our sensitivity experiments (not shown). These additional analyses suggest the primary reason for the tropical cloud differences is mean state SST between CCSM3-NEWSOM and CCSM3-OLDSOM and the new turbulence closure scheme in the convective clouds in CCSM4-NEWSOM.

Poleward of about $60^{\circ}$ north or south, cloud fraction 
Table 3. Global annual mean climate feedbacks in $\mathrm{Wm}^{-2} \mathrm{~K}^{-1}$ from kernel method.

\begin{tabular}{lc|ccccc|cc}
\hline Model Version & $\lambda^{a}$ & $\lambda_{P}$ & $\lambda_{L R}$ & $\lambda_{w}$ & $\lambda_{\alpha}$ & $\lambda_{c}$ & $\lambda_{c}^{\mathrm{LW}}$ & $\lambda_{c}^{\mathrm{SW}}$ \\
\hline \hline CCSM3-OLDSOM T85 & -1.37 & -3.05 & -0.42 & 1.62 & 0.32 & 0.46 & 0.36 & 0.11 \\
CCSM3-NEWSOM T85 & -1.30 & -3.00 & -0.25 & 1.50 & 0.34 & 0.38 & 0.28 & 0.10 \\
CCSM4-NEWSOM 1 $^{\circ}$ & -1.16 & -2.98 & -0.10 & 1.43 & 0.32 & 0.48 & 0.23 & 0.25 \\
\hline The
\end{tabular}

a The net $\lambda$ is computed from Eq. 2 using $\Delta R_{f}=3.5 \mathrm{Wm}^{-2}$ (discussed in section 2).

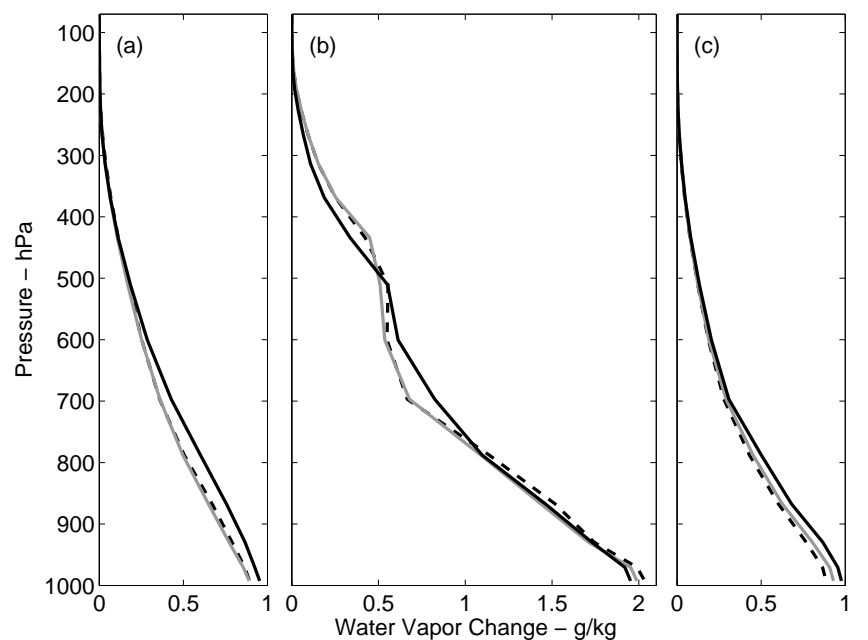

Figure 5. As in Fig. 4b but for humidity profiles.
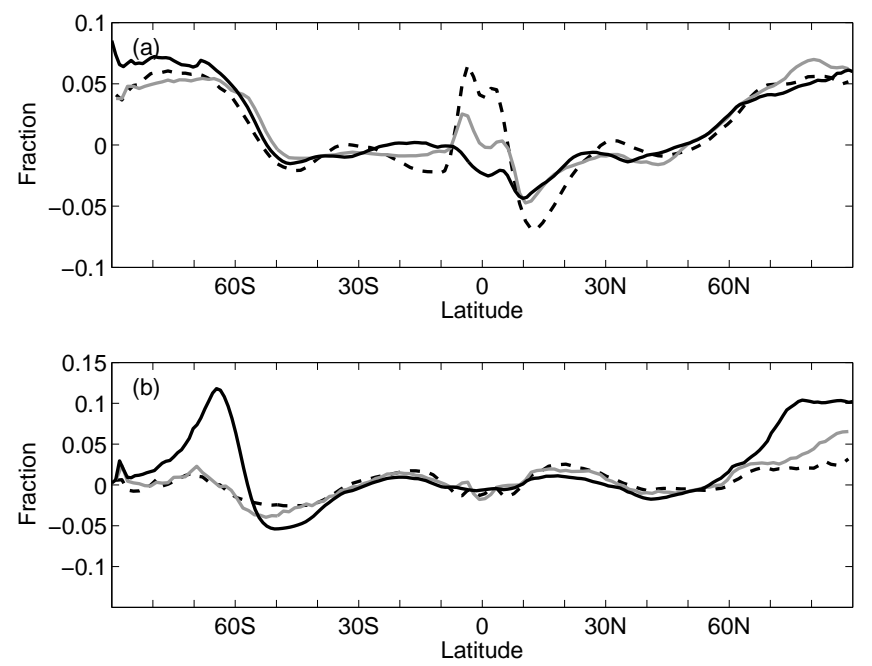

Figure 6. As in Fig. 4a but for mid to high clouds (a) and low clouds (b).

increases at all levels in all models (see Fig. 6). Low cloud fraction increases considerably more in CCSM4NEWSOM than in both CCSM3-NEWSOM and CCSM3OLDSOM in the polar regions. The polar low cloud increase in CCSM4-NEWSOM is primarily from the new freeze-dry parameterization (based on analysis of our sensitivity experiments). In contrast, there is a reduction in low clouds from $40-55^{\circ} \mathrm{S}$ in all models, but it is about twice as large in CCSM4-NEWSOM compared with CCSM3-OLDSOM and CCSM3-NEWSOM.
To interpret these and other changes and determine their effects on the climate sensitivity, we use climate feedback analysis. The underlying assumption is that the global surface air temperature responds to an imposed top of atmosphere (TOA) radiative forcing, and then feedbacks arise in response to the surface air temperature change to further alter the TOA budget. At any given point in time, the radiative imbalance at the TOA is the sum of the TOA radiative forcing $\Delta R_{f}$ and the TOA flux changes (feedback) due to changes in the global surface air temperature. The radiative kernel feedback method [Soden and Held, 2006; Soden et al., 2008] assumes that these feedback flux changes are linear with respect to the global annual average surface air temperature change $\Delta T$ :

$$
\Delta R=\Delta R_{f}+\lambda \Delta T
$$

where $\lambda$ is the net feedback parameter and $\Delta R=$ $\Delta Q-\Delta F$ is the change in absorbed shortwave radiation minus the change in outgoing longwave radiation at the TOA due to both the imposed forcing and the climate response (i.e., feedbacks). Here we have chosen the sign convention that positive $\lambda$ indicates a positive feedback (enhances climate changes). For the kernel feedback method, $\Delta R, \Delta R_{f}$, and $\lambda$ may vary spatially, but $\Delta T$ is always averaged globally. Thus $\lambda$ can be viewed as an efficiency of fluxing heat out the TOA for a given global mean temperature change.

The kernel method separates climate feedbacks into different components:

$$
\lambda=\lambda_{P}+\lambda_{L R}+\lambda_{w}+\lambda_{\alpha}+\lambda_{c}+r
$$

where $\lambda_{P}$ is the Planck feedback, $\lambda_{L R}$ is the lapse-rate feedback, $\lambda_{w}$ is the water-vapor feedback, $\lambda_{\alpha}$ is the surface albedo feedback, $\lambda_{c}$ is the cloud feedback, and $r$ is a residual which results from the nonlinear contributions to the feedback parameter or other radiative elements that are not included in the decomposition. We assume that the Planck, lapse-rate, water vapor, and surface albedo feedback parameters are independent of the climate state (at least for the range of states simulated here), and we calculate these feedbacks by combining the changes in these quantities in the double $\mathrm{CO}_{2}$ experiments with the pre-calculated radiative kernels of Shell et al. [2008]. We use the adjusted cloud radiative forcing to estimate cloud feedback following Soden et al. [2008]. The cloud component can be further broken down into shortwave and longwave feedbacks $\left(\lambda_{c}^{\mathrm{LW}}\right.$ 
and $\lambda_{c}^{\mathrm{SW}}$ ) according to their influence on $\Delta Q$ and $\Delta F$ separately. The same is true for $\lambda_{w}$; however, the shortwave component of the water-vapor feedback is nearly always the same so the longwave component accounts for most of the range in $\lambda_{w}$.

Table 3 lists the global annual mean net feedbacks and their components. The strong negative Planck feedback is relatively similar among the models, as expected. The (negative) lapse-rate feedback varies the most among the different model versions, with a steady decrease from CCSM3-OLDSOM to CCSM3NEWSOM to CCSM4-NEWSOM, while the (positive) water vapor feedback decreases, partially compensating for the lapse rate feedback decrease. The global average albedo feedback changes little.

Net cloud feedback decreases from CCSM3-OLDSOM to CCSM3-NEWSOM, and then increases from CCSM3NEWSOM to CCSM4-NEWSOM, resulting in little change from CCSM3-OLDSOM to CCSM4-NEWSOM. However, the longwave and shortwave cloud feedbacks, which are both positive, change slightly more. In CCSM3-OLDSOM, the positive cloud feedback was primarily due to the cloud longwave radiative response [Shell et al., 2008], while in CCSM4-NEWSOM, the shortwave and longwave radiative responses are about equal in magnitude.

Global average feedback values are often the result of compensation between regions of positive and negative feedbacks (especially for the lapse-rate and cloud feedbacks). Since the global mean values can hide some of the regional changes in feedbacks parameters, it is useful to consider the spatial feedback pattern.

The sign of the regional lapse-rate feedback (Fig. 7) is generally the same for all the models, except in the eastern tropical Pacific, but the magnitudes of the regional feedbacks differ among models. The lapse-rate feedback is most negative (results in the most outgoing longwave radiation increase with increasing temperature) where the lapse rate decreases the most in the doubling $\mathrm{CO}_{2}$ experiment. Figure $4 \mathrm{~b}$ shows that CCSM3-OLDSOM has the largest temperature change in the tropical upper troposphere (corresponding to the largest lapse rate decrease), so the CCSM3-OLDSOM has the most negative tropical lapse-rate feedback, except on the equator in the eastern tropical Pacific. CCSM4-NEWSOM, conversely, has the weakest negative tropical lapse rate feedback. At middle and high latitudes, all models show a transition to a positive lapse rate feedback, with CCSM4-NEWSOM having the largest positive lapse-rate feedback and CCSM3OLDSOM the smallest. Thus, CCSM4-NEWSOM is generally more positive regionally compared with the other models, so the global average lapse-rate feedback, while still negative, is small, while CCSM3-OLDSOM has the largest global average feedback.

The lapse-rate feedback variations in the tropics among the model versions are roughly opposite to their water-vapor feedback variations, except in the eastern tropical Pacific. For example, in the tropics CCSM4NEWSOM has the least negative lapse-rate feedback and the least positive water-vapor feedback. This partial compensation is expected because the relative humidity changes little when $\mathrm{CO}_{2}$ is doubled; however, the global average feedback differences among models are larger for the lapse-rate than water vapor feedbacks, so the net effect is an increase in climate sensitivity from CCSM3-OLDSOM to CCSM3-NEWSOM to CCSM4NEWSOM.

Kiehl et al. [2006] reported that the CCSM3-OLDSOM at T85 resolution overpredicts clouds in the lowest model level in the eastern tropical Pacific at $1 \mathrm{XCO}_{2}$ but not at $2 \mathrm{XCO}_{2}$. It is in this region that the lapserate feedback is strongly positive in CCSM3-OLDSOM. There is only slight evidence for this problem in the CCSM3-NEWSOM at T85 resolution, and therefore the differing mean state SST or the unphysical forcings in the OLDSOM must exacerbate the problem. The problem is not present in CCSM4 at any resolution or model configuration.

Aside from the eastern tropical Pacific, shortwave and longwave cloud feedbacks have opposite signs for a given model version. Local maxima and minima tend to be larger in magnitude in CCSM3-OLDSOM. Shortwave cloud feedback especially is more homogeneous in CCSM4-NEWSOM compared to CCSM3-OLDSOM and even CCSM3-NEWSOM (see Fig. 8), except it retains a consistent positive, high magnitude in the midlatitudes of the Southern Hemisphere. In this region, Fig. 6 indicates low clouds decline sharply when $\mathrm{CO}_{2}$ is doubled in CCSM4-NEWSOM. This region is equatorward of the sea ice zone, and therefore the cloud decrease does little to amplify sea ice albedo feedback here. However, at the poles, low clouds expand considerably in CCSM4-NEWSOM and mask the sea ice retreat from the TOA perspective.

The pattern of longwave cloud feedback in CCSM4NEWSOM is also more homogeneous than in CCSM3NEWSOM, which in turn is more homogeneous than in CCSM3-OLDSOM. The region of strong negative longwave cloud feedback in the tropical Pacific and near Indonesia present in CCSM3-OLDSOM are gone in CCSM4-NEWSOM. These are regions where medium and high clouds decrease in CCSM3-OLDSOM but change little in CCSM4-NEWSOM when $\mathrm{CO}_{2}$ is doubled.

\subsection{Dependence on the SOM formulation}

The ECS differs by as much as $0.27^{\circ} \mathrm{C}$ depending on the SOM formulation (i.e., comparing CCSM3NEWSOM and CCSM3-OLDSOM at the same resolution). This is roughly half the difference between CCSM3-OLDSOM and CCSM4-NEWSOM at similar resolutions. There are three issues that might affect the climate response with regard to the SOM formulation: 

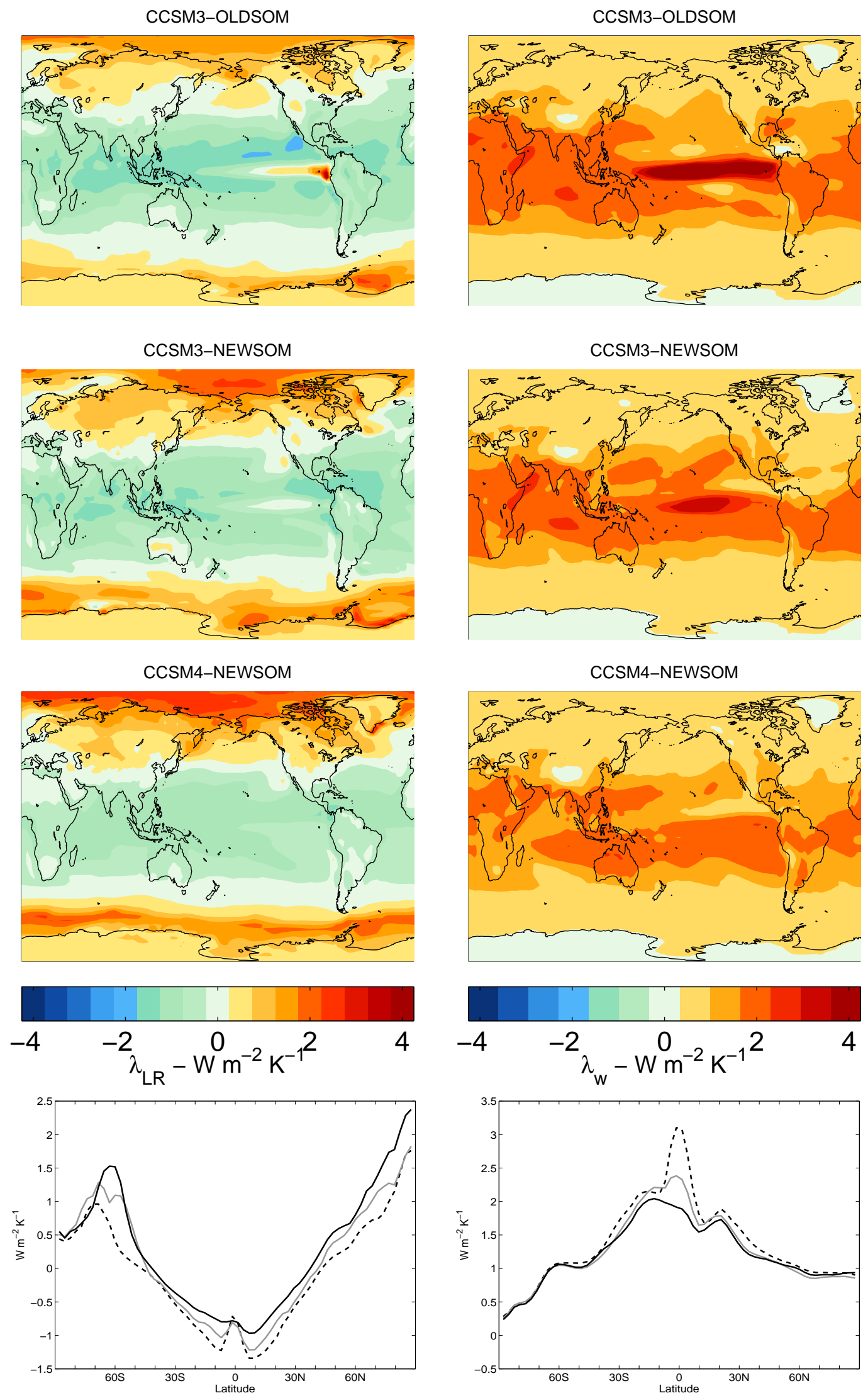

Figure 7. Feedbacks from the kernel method for lapse rate (column 1) and longwave water vapor (column 2) in $\mathrm{Wm}^{-2} K^{-1}$. Line colors for zonal mean plots as in Fig. 4. 

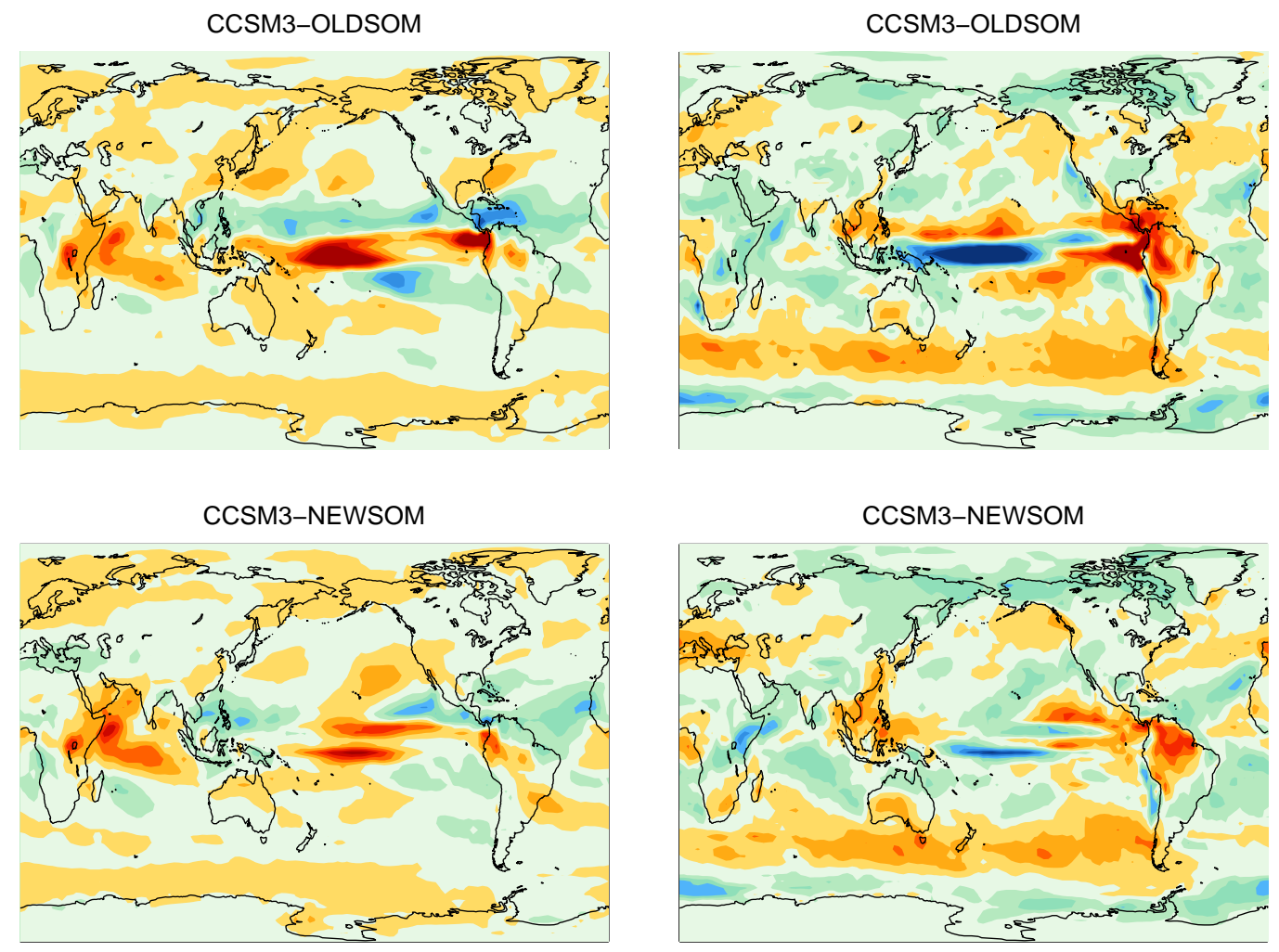

CCSM4-NEWSOM

CCSM4-NEWSOM
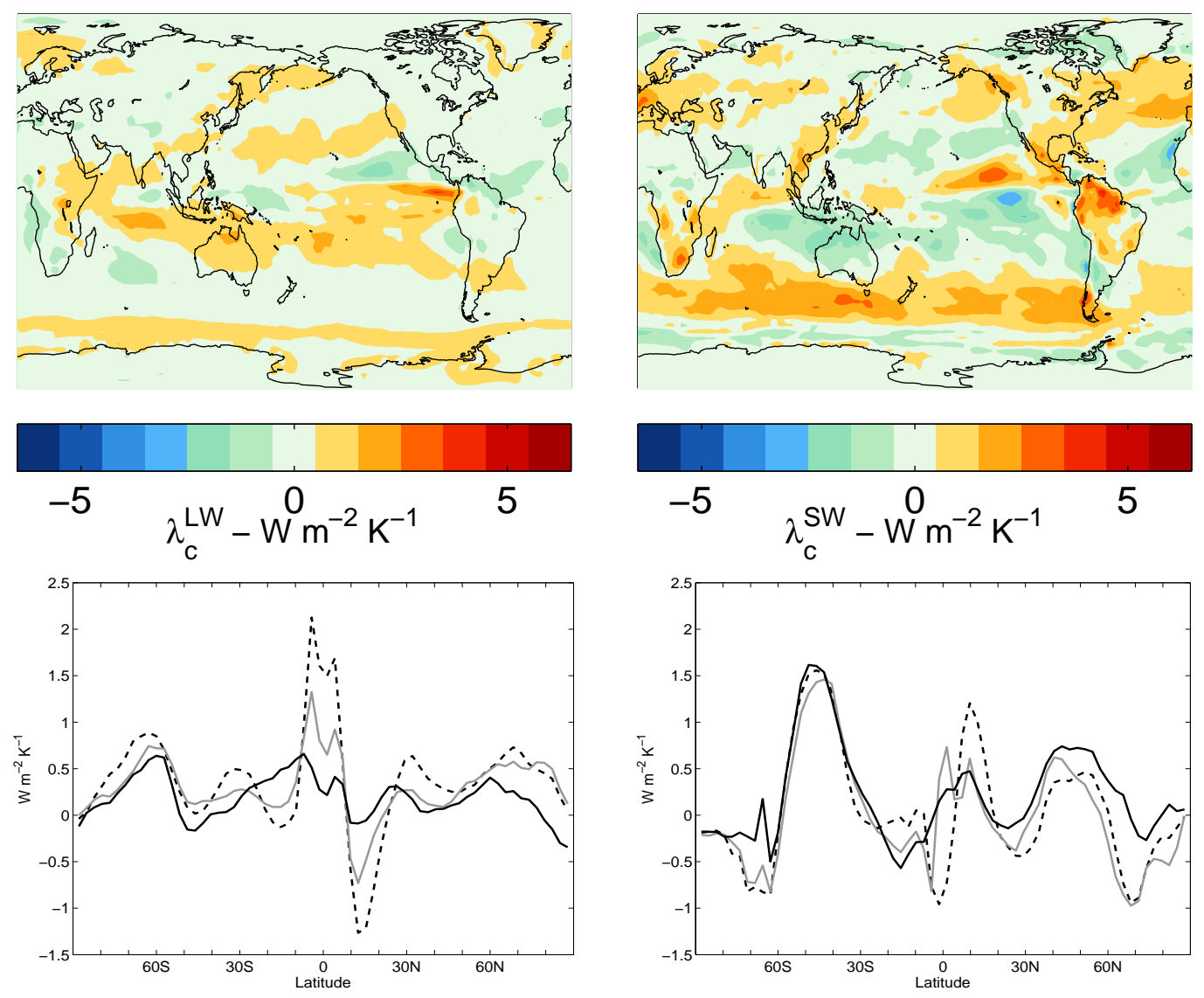

Figure 8. As in Fig. 7 but for longwave cloud (column 1) and shortwave cloud (column 2) in $\mathrm{Wm}^{-2} K^{-1}$. 
One is the influence of the unphysical forcings in the OLDSOM (see Fig. 1), second is the influence of differences in the mean state of the climate, and third is the differences in sea ice physics. Numerous studies have shown that the climate response depends on the horizontal structure of climate forcings [e.g., Hansen et al., 1997], while only a few have found a small (10-20\% change in effective climate sensitivity) dependence on climate state [e.g., Senior and Mitchell, 2000; Boer and $\mathrm{Yu}, 2003 \mathrm{a}$ ] or sea ice physics [e.g., Holland et al., 2001].

Table 4. Equilibrium climate sensitivity in a series of runs with altered slab-ocean model physics in CCSM3 OLDSOM.

\begin{tabular}{cl}
\hline$\Delta T_{\text {eq }}$ in ${ }^{\circ} \mathrm{C}$ & Run Description \\
\hline \hline 2.53 & T42, original run with standard \\
& physics, which has on-the-fly adjust- \\
& ment to $Q_{\text {flx }}$ and does not account for \\
& latent heat of snow falling into ocean \\
& T42, eliminating the unphysical forc- \\
& ing from just the on-the-fly adjust- \\
& ment to $Q_{\text {flx }}$ \\
& T42, eliminating the unphysical forc- \\
& ing from both the latent heat of snow \\
& falling into ocean and the on-the-fly \\
& adjustment to $Q_{\text {flx }}$ \\
& T85, original run with standard \\
& physics, which has on-the-fly adjust- \\
& ment to $Q_{\text {flx }}$ and does not account for \\
& latent heat of snow falling into ocean \\
& T85, eliminating the unphysical forc- \\
& ing from both the latent heat of snow \\
& falling into ocean and the on-the-fly \\
& adjustment to $Q_{\text {flx }}$
\end{tabular}

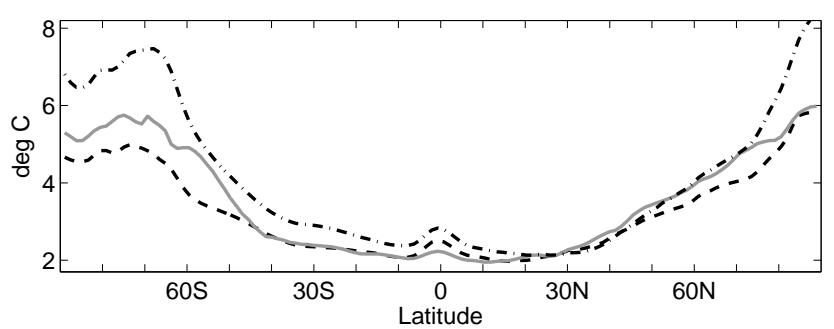

Figure 9. Zonal mean surface air temperature change from doubling $\mathrm{CO}_{2}$ in CCSM3-NEWSOM T85 (solid grey), CCSM3-OLDSOM T85 (dashed black), and CCSM3-OLDSOM T85 with both unphysical forcings eliminated (dot-dashed black).

The net feedback in CCSM3 is generally higher in the polar regions, owing to the ice-albedo and lapse-rate feedback (see section 3.1), precisely where both unphysical climate forcings in the OLDSOM are sharply negative. Thus, we might expect the unphysical forcings to inhibit feedback, and, hence, the climate sensitivity. We ran sensitivity experiments with the CCSM3 to evaluate the consequences of both unphysical forcings (see Table 4).
We eliminated the unphysical forcings in $1 \mathrm{XCO}_{2}$ and $2 \mathrm{XCO}_{2}$ sensitivity experiments in the CCSM3OLDSOM by taking into account the latent heat of snow falling into the ocean, while simultaneously fixing the on-the-fly adjustments (so they are not on-the-fly anymore) to the $Q_{\mathrm{flx}}$. We did this by first extracting the climatological mean of the on-the-fly adjustments from the original $1 \mathrm{XCO}_{2}$ run of Kiehl et al. [2006]. We then increased the $Q_{\mathrm{flx}}$ that is normally used as input to CCSM3-OLDSOM by the climatology of the on-thefly adjustments along with the latent heat of the climatological mean rate of snow falling into the ocean from the original $1 \mathrm{XCO}_{2}$ run. Finally, this modified $Q_{\text {flx }}$ was input to the CCSM3-OLDSOM with minor code changes to account for snowfall in $F_{\text {net }}$ and eliminate the on-the-fly adjustments. The resulting sensitivity experiment at $1 \mathrm{XCO}_{2}$ by construction produces an SST and mean climate that is not significantly different from the original $1 \mathrm{XCO}_{2}$ run. However, when $\mathrm{CO}_{2}$ is doubled, ECS is $0.47^{\circ} \mathrm{C}$ higher at $\mathrm{T} 42$ resolution and $0.50^{\circ} \mathrm{C}$ higher at $\mathrm{T} 85$ resolution in the sensitivity experiments compared to the original $2 \mathrm{XCO}_{2}$ runs. The zonal mean surface warming increases at all latitudes in the Southern Hemisphere (see Fig. 9), especially in the high southern latitudes. The increase is also large in the Arctic. The regions of greatest increase in surface warming conincide with the regions where the unphysical forcings are most negative in the original OLDSOM (see Fig. 1).

Another pair of sensitivity experiments was done at T42 resolution eliminating only the unphysical forcing from the on-the-fly $Q_{\text {flx }}$ adjustments compared to the original runs, and in this case ECS is $0.26^{\circ} \mathrm{C}$ higher. We did not do this test at T85 resolution.

In summary we find that the energy sources and sinks created by the on-the-fly adjustments to the $Q_{\mathrm{flx}}$ and neglecting the latent heat of snow cause unphysical forcings in the CCSM3-OLDSOM that suppress the estimated ECS by about $0.5^{\circ} \mathrm{C}$. Because the unphysical forcings are nearly the same at T42 (not shown) and T85 resolutions (see Fig. 1), the suppressed amount is nearly independent of resolution. The CCSM3NEWSOM has neither unphysical forcing, yet the ECS of CCSM3-NEWSOM is about $10 \%$ smaller than in CCSM3-OLDSOM with the unphysical forcing eliminated (see Fig. 9). The climate response differs owing purely to differences in the mean state climate (via differences in SST and sea ice climatology in the SOMs) and/or sea ice physics.

\subsection{Sensitivity tests of new physics and parameters in CCSM4}

Next we investigate the influence of new CCSM4 physics parameterizations and the mean state climate on climate sensitivity in CCSM4 compared to CCSM3. The sensitivity experiments described in this section are done with the NEWSOM using the $Q_{\mathrm{flx}}$ constructed 
from a long control with the OGCM with standard physics and forcing in all components. Unfortunately, the best estimate of ECS woud require a new $Q_{\text {flx }}$ for each sensitivity experiment based on a new long control with the perturbed physics/forcing. This is impractical. Our failure to recalibrate the $Q_{\mathrm{flx}}$ neglects changes to the ocean heat transport (and thus the $Q_{\mathrm{flx}}$ ), which might affect the mean climate state. Thus changes to the sensitivity of ECS to perturbed physics/forcing quoted in this section are subject to the caveat that they do not include changes to the $Q_{\mathrm{flx}}$. In the remainder of this section we refer to results that are exclusively from the NEWSOM, and thus we drop the term from the model version names.

One might guess that the greater high-latitude warming in CCSM4 could be a result of the pre-industrial baseline climate in CCSM4, as compared to the presentday baseline climate in CCSM3. The expanded sea ice and snow in the pre-industrial climate could yield a greater ice-albedo feedback. However, studies have shown this to be a small or even negligible effect in the past [Rind et al., 1997; Holland and Bitz, 2003]. We tested the effect nonetheless by raising $\mathrm{CO}_{2}$ to year 2000 level (at 379ppmv) in a $1 \mathrm{XCO}_{2}$ baseline CCSM4 simulation and doubling the $\mathrm{CO}_{2}$ concentration from there. This raises $\Delta T_{e q}$ in CCSM4 by $0.16^{\circ} \mathrm{C}$ compared to the standard runs (see table 5 ), indicating an increase rather than decrease in climate sensitivity for a warmer base climate. Thus the higher ECS in CCSM4 cannot be explained by the colder pre-industrial baseline climate in CCSM4 compared to the warmer baseline climate in CCSM3. We thus consider other CCSM4 changes as possibilities for the increase in CCSM4 sensitivity.

Table 5. Equilibrium climate sensitivity in series of runs with varying physics and parameters in CCSM4NEWSOM.

\begin{tabular}{cl}
\hline$\Delta T_{e q}$ in ${ }^{\circ} \mathrm{C}$ & Run Description $^{a}$ \\
\hline \hline 3.13 & $2^{\circ}$ Standard physics \\
3.20 & $1^{\circ}$ Standard physics \\
3.36 & $1^{\circ}$ Standard physics but with year \\
& $2000 \mathrm{CO}_{2}$ concentration baseline \\
3.35 & $2^{\circ}$ Standard physics except without \\
& CCSM4's new cloud freeze-dry param- \\
& eterization [Vavrus and Waliser, 2008] \\
3.00 & $1^{\circ}$ Standard physics except revert to \\
& vegetation snow burial method from \\
& CCSM3
\end{tabular}

${ }^{a}$ In each case the qflux is from a pre-industrial CCSM4 OGCM run at the same resolution as the integration to which it is prescribed.

One significant change in CCSM4 is the freeze-dry cloud parameterization (see the model description in section 2). We tested its influence on CCSM4 climate change by conducting sensitivity experiments at $1 \mathrm{XCO}_{2}$ and $2 \mathrm{XCO}_{2}$ with the parameterization eliminated. The primary effect of the freeze-dry parameterization is to reduce low cloud fraction by about $10-20 \%$ in the polar regions in the $1 \mathrm{XCO}_{2}$ climate. The effect is diminished at $2 \mathrm{XCO}_{2}$, and therefore including this parameterization in CCSM4 causes a large increase in low cloud amount in the polar regions when $\mathrm{CO}_{2}$ is doubled. Without this parameterization, the polar regions warm about $0.5^{\circ} \mathrm{C}$ more and $\Delta T_{e q}$ is $0.22^{\circ} \mathrm{C}$ higher (Table 5 ). Thus, its inclusion in CCSM4 reduces ECS and masks other factors that raise ECS in CCSM4 compared to CCSM3.

We were able to identify one parameterization change that does increase ECS in CCSM4. It involves how snow buries vegetation when it accumulates at the surface. We performed a doubled $\mathrm{CO}_{2}$ experiment with a version of CCSM4 with the old CCSM3 snow burial parameterization, resulting in a decreased ECS. Thus, the new parameterization in CCSM4 increases ECS by $0.20^{\circ} \mathrm{C}$. Despite the increased sensitivity from this parameterization change, we found no increase to the global mean surface albedo feedback in CCSM4 compared to CCSM3 (see Table 3). There must be a compensating change to the surface albedo parameterization that cancels the effects from the snow burial changes on the whole.

In total, our attempt at explaining the higher ECS in CCSM4 compared to CCSM3 through sensitivity exeriments revealed no single major cause. Lowering the baseline $\mathrm{CO}_{2}$ in CCSM4, lowers ECS slightly, all other things being equal. The new freeze-dry cloud parameterization also lowers ECS. Among the parameters/forcings we isolated in this section, we found only the new snow burial rate parameterization raises ECS, but it is only a partial explanation for the differences between CCSM4 and CCSM3. The diagnostic analysis of section 3.1 identified changes in deep convection as a major factor in altering lapse-rate, water vapor, and cloud feedbacks, but we did not do sensitivity experiments to isolate effects from the new deep convection parameterization on ECS.

\section{Transient versus equilibrium climate sensitivity and the role of ocean dynamics}

Because the NEWSOM reproduces the OGCM's SST and sea ice cover, transient and equilibrium perturbation experiments can be compared consistently between runs with NEWSOM and OGCM. The climate difference between them cleanly shows the role of ocean dynamics and deep ocean warming, without being confused by differing states of the SST or sea ice cover and sea ice physics. In this section we compare the climate response of CCSM3 and CCSM4 to doubling $\mathrm{CO}_{2}$ in transient integrations (with OGCM) and equilibrium integrations (with NEWSOM). We then delve further 
Table 6. Transient climate response, effective climate sensitivity and TOA radiative imbalance in $1 \% \mathrm{CO}_{2}$ ramp OGCM runs at time of doubling; equilibrium climate sensitivity from NEWSOM runs; and ratios of transient climate response to equilibrium climate sensitivity and effective climate senstivity to equilibrium climate sensitivity.

\begin{tabular}{lcccccc}
\hline Model Version & $\Delta T(70 \mathrm{yr})$ & $\Delta T_{\text {eff }}(70 \mathrm{yr})$ & $\Delta R(70 \mathrm{yr})$ & $\Delta T_{\text {eq }}$ & $\frac{\Delta T(70 \mathrm{yr})}{\Delta T_{\text {eq }}}$ & $\frac{\Delta T_{\text {eff }}(70 \mathrm{yr})}{\Delta T_{\text {eq }}}$ \\
& ${ }^{\circ} \mathrm{C}$ & ${ }^{\circ} \mathrm{C}$ & $\mathrm{Wm}^{-2}$ & ${ }^{\circ} \mathrm{C}$ & & \\
\hline \hline CCSM3 T85 & 1.54 & 2.37 & 1.23 & 2.86 & 0.54 & 0.83 \\
CCSM4 1 & 1.72 & 2.64 & 1.22 & 3.20 & 0.54 & 0.83 \\
\hline
\end{tabular}

into the transient behavior of the CCSM4-OGCM for which we have a 309 year long integration following an instantaneous $\mathrm{CO}_{2}$ doubling. All integrations described in this section are at the highest resolution considered in this study (T85 for CCSM3 and $1^{\circ}$ for CCSM4).

We first examine the transient behavior of CCSM3OGCM and CCSM4-OGCM in 1\% per year (continuously updated) $\mathrm{CO}_{2}$ ramp integrations. Standard metrics that characterize the global annual mean transient response at the time of doubling (year 70) are listed in table 6 . The global annual surface air temperature change at the time of $\mathrm{CO}_{2}$ doubling is known as the transient climate response (TCR, $\Delta T(70 \mathrm{yr}))$. The effective climate sensitivity at the time of $\mathrm{CO}_{2}$ doubling $\left(\Delta T_{\text {eff }}(70 y r)\right)$, as defined by Murphy [1995], is an estimate of the ECS by extrapolating the TCR to the time when the TOA radiative imbalance goes to zero while assuming climate feedbacks are constant in time and equal to the magnitude at year 70. In practice, the timeseries $\Delta T_{\text {eff }}(t)$ is equal to $\Delta T(t)$ scaled by $\Delta R_{f} /\left(\Delta R_{f}-\Delta R(t)\right)$.

The TCR and $\Delta T_{\text {eff }}(70 y r)$ are both smaller in CCSM3 than in CCSM4. Yet, the global annual mean TOA radiative imbalance $(\Delta R(70 \mathrm{yr}))$ is nearly identical in the models. On the global annual mean the ocean heat uptake, by which we mean the surface heat flux into the ocean, is nearly equivalent to $\Delta R$. The greater the ocean heat uptake, the more suppressed the surface warming and the greater the $\Delta R$. Despite the apparent logic of this statement, the amount the surface warming is suppressed is not exclusively a function of ocean heat uptake in cross-model interecomparisons (see, e.g., IPCC 1990). Winton et al. [2010] argues this is because different models respond differently to a given amount of ocean heat uptake. However, our two models do appear to supress warming about the same amount for a given amount of heat uptake, as $\Delta R(70 \mathrm{yr})$ and the ratio of TCR to ECS (and of $\Delta T(70 \mathrm{yr})_{\text {eff }}$ to ECS) is the same for the two models within a percent.

We believe that these ratios in CCSM3 and CCSM4 are nearly the same because not only is their global mean ocean heat uptake nearly the same, but the latitudinal dependence is very similar (see Fig. 10a). The rate of decline in ocean heat uptake is largest in the mid to high latitudes, where warming at equilibrium is greatest (see Fig. 4a) and feedbacks are above average in CCSM3 and CCSM4 (see Fig. 10b). We specu-
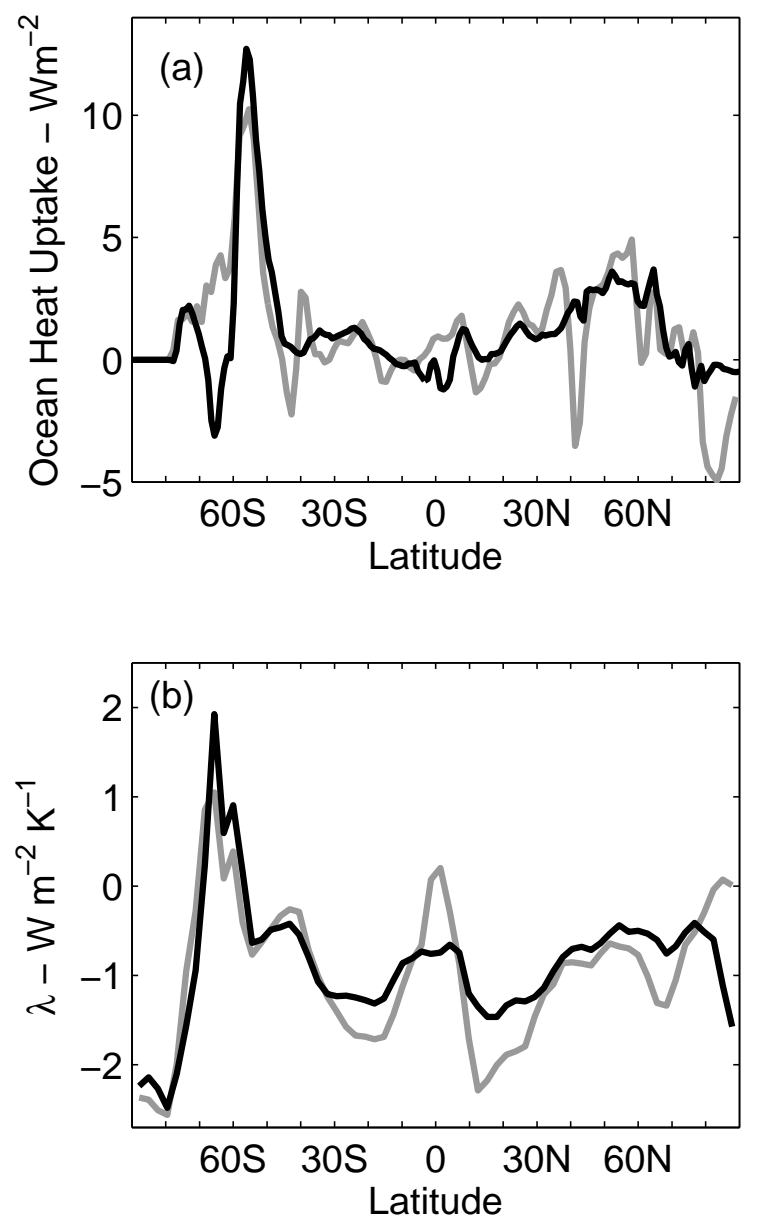

Figure 10. Zonal mean change in ocean heat uptake in $\mathrm{CO}_{2}$ ramp runs with OGCM from 30 yr means centered on the time of doubling (a) and zonal mean net feedback $\lambda$ in equilibrium runs with NEWSOM (b) for CCSM3 (grey) and CCSM4 (black). Zonal mean ocean heat uptake includes zeros over land.

late that the more polar amplified the rate of decline in ocean heat uptake, the smaller the ratios of $\Delta T(t)$ to $\Delta T_{\text {eq }}$ and $\Delta T_{\text {eff }}$ to $\Delta T_{\text {eq }}$.

We end our analysis of transient climate response in CCSM4-OGCM by examining the time dependent response of a 309 year integration with $\mathrm{CO}_{2}$ doubled instantly at the start. The timeseries of $\Delta T(t)$ (see Fig. 11a) indicates that the global annual mean warming reached at the end (about $2.5^{\circ} \mathrm{C}$ ) is still substantially below the $\operatorname{ECS}\left(\Delta T_{\mathrm{eq}}=3.20^{\circ} \mathrm{C}\right)$. Much of this dif- 

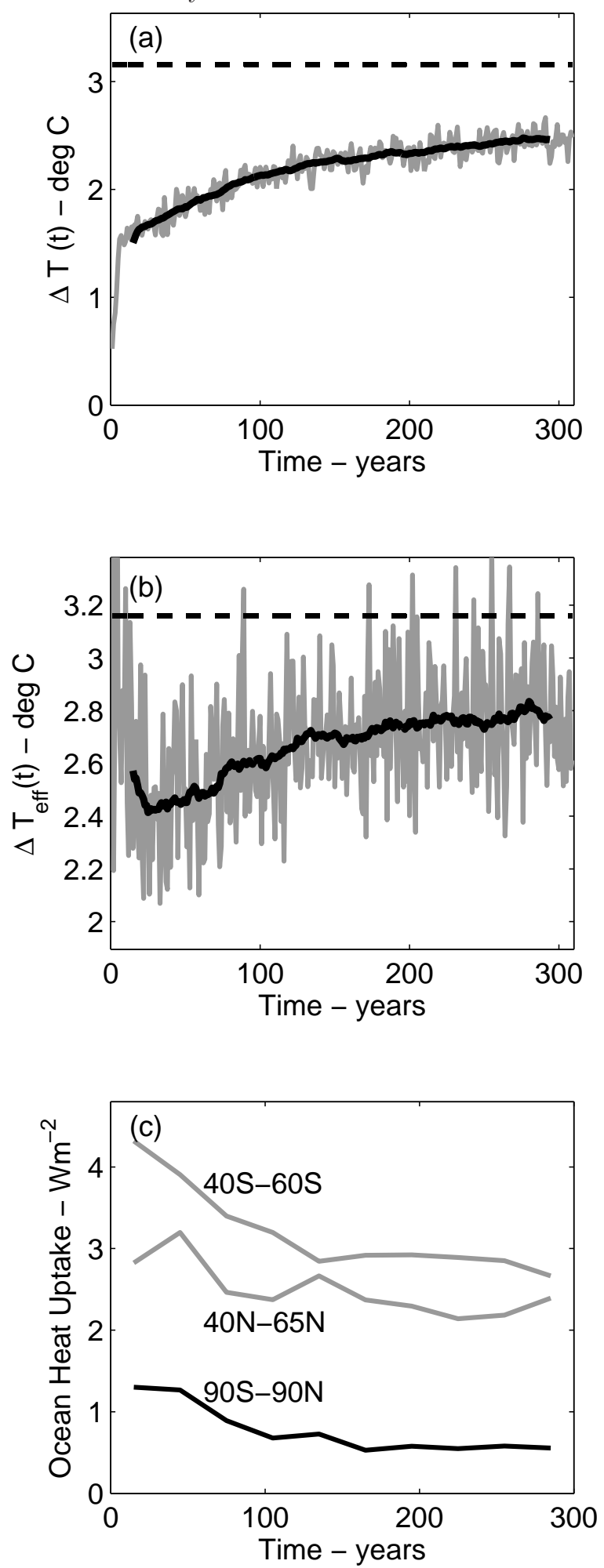

Figure 11. Time-dependent variables from CCSM4OGCM integration with $\mathrm{CO}_{2}$ doubled instantly at year 0: Global mean surface air temperature change (a) and effective climate sensitivity (b), computed annually (grey) and smoothed with a 30 yr running mean (black solid). Ocean heat uptake averaged over latitude ranges as indicated for 30 year means, including zeros over land (c). ECS is dashed in (a) and (b). ference arises from greater warming in the NEWSOM compared to the OGCM in the Pacific and Atlantic sectors of the Southern Ocean and just south of Greenland (see Fig. 12), all regions of deep mixing and large ocean heat uptake. The OGCM SST warms more than the NEWSOM in the Barents Sea - a result seen in CCSM3 as well [Bitz et al., 2006].

The timeseries of $\Delta T_{\text {eff }}(t)$ (see Fig. 11b) is noisier than $\Delta T(t)$. Yet, the smoothed $\Delta T_{\text {eff }}(t)$ is alway less than the ECS, and it is unclear if $\Delta T_{\text {eff }}(t)$ is asymptoting to $\Delta T_{\text {eq }}(t)$. The time dependence of $\Delta T_{\text {eff }}(t)$ has been attributed to a time dependence of climate feedbacks [e.g., Senior and Mitchell, 2000]. Indeed, as defined in Eq 2, the global mean net $\lambda$ (not shown) is inversely proportionate to $\Delta T_{\text {eff }}(t)$, but the time dependence of $\lambda$ may be an indication that Eq 2 is not an optimal definition of feedback. We propose that the time dependence of the pattern of ocean heat uptake is possibly a more fundamental factor that affects the time evolution of estimates of climate sensitivity. Ocean heat uptake declines about $50 \%$ faster in the mid to high latitudes (averaging in zeros over land) than it does in other regions (see Fig. 11c), and therefore, $\Delta T_{\text {eff }}(t)$ should be less suppressed in time. The transient response of $\Delta T_{\text {eff }}(t)$ is roughly in line with the reduction in ocean heat uptake from $40^{\circ} \mathrm{S}-60^{\circ} \mathrm{S}$. The ocean heat uptake may never reach zero locally if doubling $\mathrm{CO}_{2}$ forces permanent changes in the ocean heat flux convergence, which would mean that $\Delta T_{\mathrm{eq}}$ may never quite reach the ECS of the CCSM4-NEWSOM, even if the global annual mean ocean heat uptake reaches zero.

Similarly, the unphysical forcings in the CCSM3OLDSOM suppress $\Delta T_{\text {eq }}$ because, like the ocean heat uptake in CCSM-OGCM, the unphysical forcings remove heat from the atmosphere in regions of above average positive feedback.

Gregory et al. [2004] suggested another way of estimating the effective climate sensitivity of a climate model can be obtained by regressing $\Delta T(t)$ on $\Delta R(t)$ and extrapolating the regression to $\Delta R=0$. The method is attractive because it requires no a priori estimate of $R_{f}$. For the 309 year instant doubling integration of CCSM4, Gregory et al.'s method gives an effective climate sensitivity of $2.80^{\circ} \mathrm{C}$ (see Fig. 13), which is nearly identical to the average of the last $30 \mathrm{yr}$ of $\Delta T_{\text {eff }}$ from Fig. $11 \mathrm{~b}\left(2.78^{\circ} \mathrm{C}\right)$ using the method of Murphy [1995]. The excellent agreement can be seen graphically as the near intersection of dashed and dot-dashed lines at $\Delta R=0$ in Fig. 13 .

\section{Conclusions}

The equilibrium climate sensitivity of the CCSM4 from doubling $\mathrm{CO}_{2}$ is $3.20^{\circ} \mathrm{C}$ for $1^{\circ}$ horizontal resolution in each component. This is about a half degree Celsius higher than was cited for CCSM3 by Kiehl et al. [2006] and Randall et al. [2007]. When comparing runs 

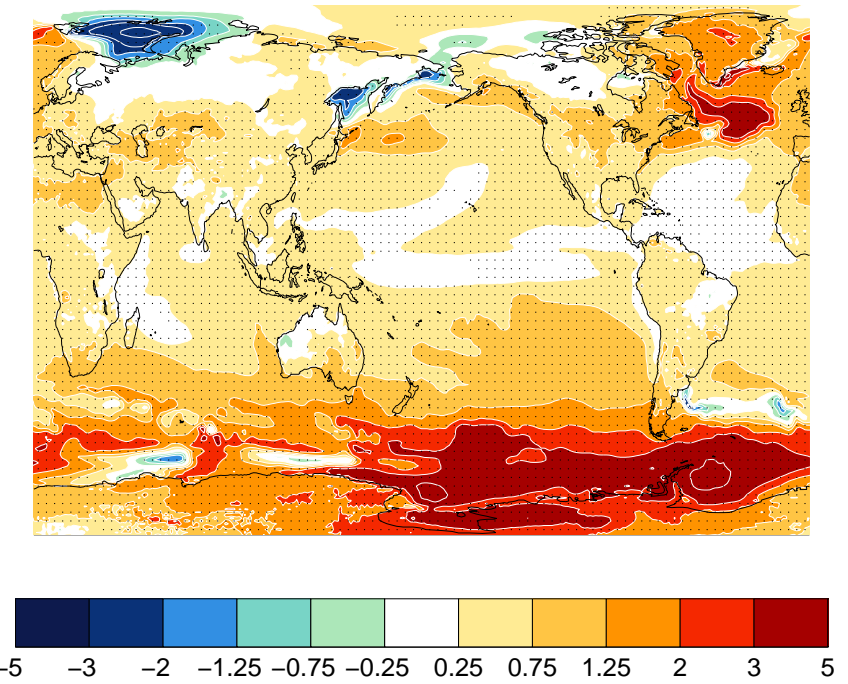

Figure 12. Surface air temperature change in ${ }^{\circ} \mathrm{C}$ (difference of $\Delta T$ 's) from doubling $\mathrm{CO}_{2}$, CCSM4NEWSOM $1^{\circ}$ at equilibrium (yr 31-60) minus CCSM4OGCM $1^{\circ}$ after 3 centuries (yr 280-309) in the instant $\mathrm{CO}_{2}$ doubling experiment. Dots show regions where the surface temperature is significantly different at the $95 \%$ confidence interval.

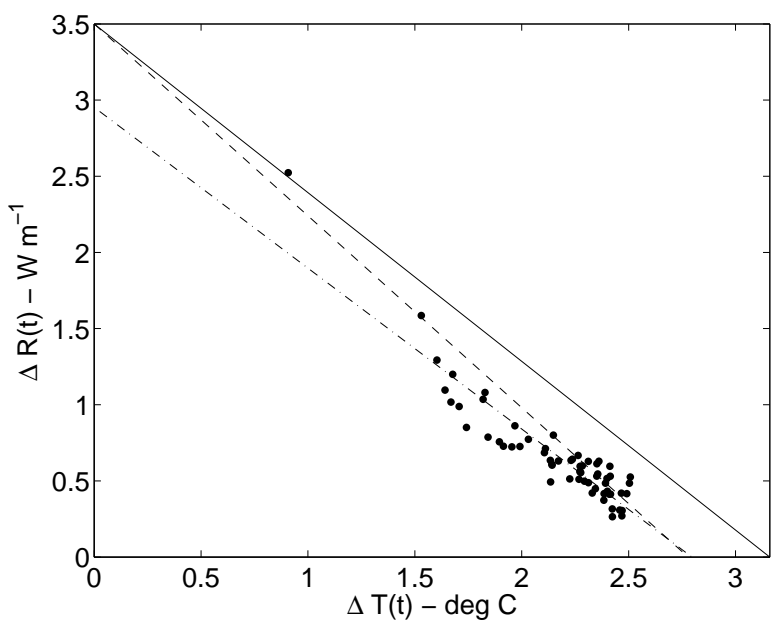

Figure 13. Scatterplot of global mean TOA radiative balance against surface air temperature for pentadal averages of the CCSM4 instant $\mathrm{CO}_{2}$ doubling experiment. The solid line is through $\left[0, R_{f}\right]$ and $\left[\Delta T_{\text {eq }}, 0\right]$, the dashed line is through $\left[0, R_{f}\right]$ and $\left[\Delta T_{\text {eff }}(280-309)\right.$, $\left.\Delta R_{\text {eff }}(280-309)\right]$, and the dot-dashed line is the regression line. of with the same slab-ocean formulation, the ECS of the CCSM4 is higher than in CCSM3 by about $0.35^{\circ} \mathrm{C}$. Climate sensitivity is higher in CCSM4 primarily owing to a reduction in warming in the upper troposphere relative to the surface warming at all latitudes. The next most important factor is an increase in shortwave cloud feedback, which is primarily the result of a relative reduction in low cloud expansion from doubling $\mathrm{CO}_{2}$ in CCSM4 compared to CCSM3. These changes are a result of modifications to the convective cloud scheme. Adjustments to the parameterization of snow burial of vegetation increase ECS by $0.20^{\circ} \mathrm{C}$, mostly due to greater warming of high northern land surfaces. The ECS in the CCSM4 would be even higher if it were not for the change in baseline $\mathrm{CO}_{2}$ level (CCSM4's climate sensitivity is relative to a pre-industrial climate while CCSM3's is present day) and the new freeze-dry cloud parameterization.

The formulation of the slab ocean in CCSM4 is substantially revised from the SOM that was released with CCSM3. We implemented the NEWSOM formulation in CCSM3 so we could isolate its effect in a model with the same physics otherwise. The new formulation causes as much as a $0.25^{\circ} \mathrm{C}$ increase in ECS, with regional warming that is $1-3^{\circ} \mathrm{C}$ greater in the polar regions and $0.5-3^{\circ} \mathrm{C}$ less in the eastern tropical Pacific and western North Atlantic. We identified unphysical forcings due to on-the-fly adjustments to the prescribed ocean heat transport convergence and from neglecting the latent heat of snow falling into the ocean in CCSM3OLDSOM that suppress ECS by almost $0.5^{\circ} \mathrm{C}$. The fact that this is more than the difference between the CCSM3-OLDSOM and CCSM3-NEWSOM at similar resolutions is an indication that the difference in mean state of the SST and sea ice between the two formulation also influences ECS by about $0.25^{\circ} \mathrm{C}$.

The NEWSOM in CCSM4 (or CCSM3) attempts to reproduce the SST and sea ice climatology from an integration of the CCSM4 (or CCSM3) with a full-depth OGCM, while the OLDSOM in CCSM3 attempts to reproduce an observed SST and sea ice climatology. The NEWSOM is integrated with the same sea ice model as in the OGCM, which by default includes sea ice dynamics, while sea ice in the OLDSOM is motionless. The new features of the NEWSOM offer an estimate of the ECS that is potentially more consistent with the surface temperature change using the CCSM4 with an OGCM run to equilibrium. Indeed the ECS in CCSM3-NEWSOM agrees within $0.01^{\circ} \mathrm{C}$ with the surface temperature change 3,000 years after instantly doubling $\mathrm{CO}_{2}$ in an integration of CCSM3 with an OGCM [see Danabasoglu and Gent, 2009], in integrations at the same resolution.

In integrations with an OGCM where $\mathrm{CO}_{2}$ is ramped and then stabilized at double its starting value, the transient climate response and effective climate sensitivity of CCSM3 and CCSM4 scale by the same fac- 
tor relative to the ECS of the corresponding SOM version (CCSM3-NEWSOM and CCSM4-NEWSOM). The TCR is 0.54 times the ECS, and the effective climate sensitivity at the time of $\mathrm{CO}_{2}$ doubling is 0.83 times the ECS.

We argue that these factors are controlled by the spatial pattern of ocean heat uptake, which on the zonal mean is broadly the same in CCSM3 and CCSM4. Ocean heat uptake suppresses the local surface warming with a spatial pattern that matters because feedbacks also vary spatially. Suppressing warming where feedbacks are most positive is most effective at suppressing TCR (and hence effective climate sensitivity). In the case of CCSM3 and CCSM4, the ocean heat uptake is highest just equatorward of the sea ice edge, where feedbacks are on average more positive than they are globally.

When we examined the transient response in more detail in the CCSM4, we found that the effective climate sensitivity increases over time, which we attribute to the fact that the ocean heat uptake decreases faster in the region just equatorward of the sea ice edge than it does globally.

The intermodel range of ECS among models analyzed in the IPCC AR4 [table 8.2, Randall et al., 2007] is $2.1-4.4^{\circ} \mathrm{C}$, which is nearly three times greater than the range of ECS among CCSM3 and CCSM4 runs at the various resolutions and slab ocean formulations listed in table 2. The principle reason cited for the spread among models in IPCC AR4 is disagreement in the magnitude of cloud feedback. While for CCSM3 and CCSM4, differences in the combined lapse-rate and water-vapor feedbacks are just as important as differences in cloud feedback. Among IPCC AR4 models, the ECS of CCSM3-OLDSOM was tied for 4th lowest with three other models out of 19 total. The ECS of CCSM4NEWSOM would have been squarely in the middle of the pack. The TCR of CCSM3-OGCM was also tied for 4th lowest with three other models out of 19 in the IPCC AR4 [Randall et al., 2007, table 8.2]. The TCR of CCSM4-OGCM would have been slightly above the median, tied for 11th lowest.

Acknowledgments. We thank David Lawrence for advice and code changes to test the snow burial rate parameterization. We thank Kelly McCusker and Michael Winton for helpful discussions and two anonymous reviewers whose comments substantially improved this paper. The authors gratefully acknowledge the support of the National Science Foundation through grants ARC-0909313 and ARC-0938204 (CMB), ATM-0904092 (KMS), and ARC-0908675 (PRG and DAB) and the Department of Energy grant ER64433 (CMB). Computing resources were provided by the Climate Simulation Laboratory at NCAR's Computational and Information Systems Laboratory (CISL). NCAR and CISL are sponsored by the National Science Foundation and other agencies.

\section{References}

Bitz, C. M., 2008: Some aspects of uncertainty in predicting sea ice thinning. in E. deWeaver, C. M. Bitz and B. Tremblay, editors, Sea Ice Decline, pp. 63-76. AGU.

Bitz, C. M., P. R. Gent, R. A. Woodgate, M. M. Holland and R. Lindsay, 2006: The influence of sea ice on ocean heat uptake in response to increasing co2. J. Climate, 19, 2437-2450.

Bitz, C. M. and G. H. Roe, 2004: A mechanism for the high rate of sea-ice thinning in the arctic ocean. J. Climate, 17, 3623-31.

Boer, G. J. and B. Yu, 2003a: Climate sensitivity and climate state. Clim. Dyn., 21, 167-176.

Boer, G. J. and B. Yu, 2003b: Climate sensitivity and response. Clim. Dyn., 20, 415-429.

Boer, G. J. and B. Yu, 2003c: Dynamic climate sensitivity. Geophys. Res. Lett., 30, 1135, doi:10.1029/2002GL016549.

Briegleb, B. P. and B. Light, 2007: A Delta-Eddington multiple scattering parameterization for solar radiation in the sea ice component of the Community Climate System Model. NCAR Tech. Note 472+STR, pp. 100.

Collins, W. D., C. M. Bitz, M. Blackmon, G. B. . Bonan, C. S. Bretherton, J. A. Carton, P. Chang, S. Doney, J. J. Hack, T. Henderson, J. T. Kiehl, W. G. Large, D. McKenna, B. D. Santer, and R. Smith, 2006: The Community Climate System Model Version 3, CCSM3. J. Climate, 19, 2122-2143.

Comiso, J. C., 1990: DMSP SSM/I daily and monthly polar gridded bootstratp sea ice concentrations 1990-1999. Tech. rep., NASA, Technical Report, Digital Media (updated quarterly).

Danabasoglu, G., S. Bates, B. P. Briegleb, S. R. Jayne, M. Jochum, W. G. Large, S. Peacock and S. G. Yeager, 2011: The ccsm4 ocean component. J. Climate, 24, This collection.

Danabasoglu, G. and P. R. Gent, 2009: Equilibrium climate sensitivity: Is it accurate to use a slab ocean model? $J$. Climate, 22, 2494-2499.

Gent, P., G. Danabasoglu, L. Donner, M. Holland, E. Hunke, S. Jayne, D. Lawrence, R. Neale, P. Rasch, M. Vertenstein, P. Worley, Z.-L. Yang and M. Zhang, 2011: The Community Climate System Model Version 4. J. Climate, 24, This collection.

Gregory, J. M., W. J. Ingram, M. A. Palmer, G. S. Jones, P. A. Stott, R. B. Thorpe, J. A. Lowe, T. C. Johns and K. D. Williams, 2004: A new method for diagnosing radiative forcing and climate sensitivity. Geophys. Res. Lett., L03205, 10.1029/2003GL018747.

Hansen, J., M. Sato and R. Ruedy, 1997: Radiative forcing and climate response. J. Geophys. Res., 102, 6831-6864.

Holland, M., D. Bailey, B. Briegleb, B. Light and E. Hunke, 2011: Improved sea ice shortwave radiation physics in ccsm4: The impact of melt ponds and black carbon. J. Climate, 24, This Collection.

Holland, M. M., C. Bitz and A. Weaver, 2001: The influence of sea ice physics on simulations of climate change. $J$. Geophys. Res., 106, 2441-2464.

Holland, M. M. and C. M. Bitz, 2003: Polar amplification of climate change in the Coupled Model Intercomparison Project. Clim. Dyn., 21, 221-232.

Holland, M. M., C. M. Bitz, E. C. Hunke, W. H. Lipscomb and J. L. Schramm, 2006: Influence of the sea ice thick- 
ness distribution on polar climate in CCSM3. J. Climate, 19, 2398-2414.

IPCC, 1990: Climate Change: The IPCC Scientific Assessment. p. 365pp. Cambridge University Press, Cambridge, UK, 365pp.

Kay, J., M. Holland, C. Bitz, A. Gettleman, E. BlanchardWrigglesworth, A. Conley and D. Bailey, 2011: The influence of local feedbacks and heat transport on the equilibrium arctic climate response to increased greenhous gas forcings in coupled climate models. J. Climate, 24, This collection.

Kiehl, J. T., W. D. Collins, J. J. Hack and C. Shields, 2006: The climate sensitivity of the Community Climate System Model Version 3 (CCSM3). J. Climate, 19, 25842596.

Knutson, T., 2003, revised in 2009: FMS Slab Ocean Model Technical Documentation, http://www.gfdl.noaa.gov/fms-slab-ocean-modeltechnical-documentation, accessed Feb 6, 2011.

Lawrence, D. M., K. W. Oleson, M. G. Flanner, C. G. Fletcher, P. J. Lawrence, S. Levis, S. C. Swenson and G. B. Bonan, 2011: The ccsm4 land simulation, 18502005: Assessment of surface climate and new capabilites. J. Climate, 24, This collection.

Lunt, D. J., A. M. Haywood, G. A. Schmidt, U. Salzmann, P. J. Valdes and H. J. Dowsett, 2010: Earth system sensitivity inferred rom Pliocene modelling and data. Nature Geos., 3, 60-64.

McCusker, K., D. Battisti and C. M. Bitz, 2011: Geoengineering for climate emergencies. J. Climate, 24.

McFarlane, N. A., G. J. Boer, J.-P. Blanchet and M. Lazare, 1992: The Canadian Climate Centre second-generation general circulation model and its equilibrium climate. $J$. Climate, 5, 1013-1044.

Murphy, D. M., 1995: Transient response of the Hadley Centre coupled ocean-atmosphere model to increasing carbon dioxide: Part III. Analysis of global-mean response using simple models. J. Climate, 8, 495-514.

Neale, R. B., J. H. Richter, C. Hannay, P. Rasch, A. Gettleman, D. L. Williamson, J. Caron and E. G. Zhang, $\mathrm{Wu}, 2011$ : The mean atmospheric climate of the community atmosphere model version 4 (cam4) in forced sst and coupled experiments. J. Climate, 24, This collection.

Neale, R. B., J. H. Richter and M. Jochum, 2008: The impact of convection on ENSO: From a delayed oscillator to a series of events. J. Climate, 21, 5904-5924.

Randall, D., R. Wood, S. Bony, R. Colman, T. Fichefet, J. Fyfe, V. Kattsov, A. Pitman, J. Shukla, J. Srinivasan, R. Stouffer, A. Sumi and K. Taylor, 2007: Climate models and their evaluation. in S. Solomon, D. Qin, M. Manning, Z. Chen, M. Marquis, K. Averyt, M.Tignor and H. Miller, editors, Climate Change 200\%: The Physical Science Basis. Contribution of Working Group I to the Fourth Assessment Report of the Intergovernmental Panel on Climate Change. Cambridge Univ. Press.

Richter, J. H. and P. J. Rasch, 2008: Effects of Convective Momentum Transport on the Atmospheric Circulation in the Community Atmosphere Model, Version 3. J. Climate, 21, 1487-1499.

Rind, D., R. Healy, C. Parkinson and D. Martinson, 1997: The role of sea ice in $2 \mathrm{XCO}_{2}$ climate model sesitivity. Part II: Hemispheric dependencies. Geophys. Res. Lett., 24, 1491-1494.
Schmidt, G. A. et al., 2006: Present day atmospheric simulations using GISS ModelE: Comparison to in-situ, satellite and reanalysis data. J. Climate, 19, 153-192, doi:10.1175/JCLI3612.1.

Senior, C. A. and J. F. B. Mitchell, 2000: The timedependence of climate sensitivity. Geophys. Res. Lett., 27, 2685-2688.

Shell, K., J.T.Kiehl and C. Shields, 2008: Using the radiative kernel technique to calculate climate feebacks in NCAR's Community Atmosphere Model. J. Climate, 21, 2269-2282.

Soden, B. and I. Held, 2006: An assessment of climate feedbacks in coupled ocean-atmosphere models. J. Climate, 19, 3354-3360.

Soden, B., I. Held, R. Colman, K. Shell, J. Kiehl and C. Shields, 2008: Quantifying climate feedbacks using radiative kernels. J. Climate, 21, 3504-3520.

Vavrus, S. J. and D. Waliser, 2008: An improved parameterization for simulating Arctic cloud amount in the CCSM3 climate model. J. Climate, 21, 5673-5687.

Willias, K., A. Keen, J. Crossley, C. Senior and C. Hewitt, 2000: Unified Model Documentation Paper 58 The Slab Model.

Winton, M., K. Takahashi and I. Held, 2010: Importance of ocean heat uptake efficacy to transient climate change. $J$. Climate, 23, 2333-2344.

Yi, D. and J. Zwally, 2010: Arctic sea ice freeboard and thickness. Tech. rep., National Snow and Ice Data Center, Boulder, CO, USA.

Zhang, G. and N. McFarlane, 1995: Role of convective-scale momentum transport in climate simulation. J. Geophys. Res., 100, 1417-1426.

Cecilia Bitz and Kyle Armour, Atmospheric Sciences MS 351640, University of Washington, 1013 NE 40th St., Seattle, WA, 98195-1640

Karen Shell, College of Oceanic and Atmospheric Sciences, Oregon State University,104 COAS Admin Building,Corvallis, OR, 97331-5503

Peter R. Gent, David A. Bailey, Gokhan Danabasoglu, Marika M. Holland, and Jeffrey Kiehl, National Center for Atmospheric Research, P.O. Box 3000, Boulder, CO 80307

This preprint was prepared with AGU's LATEX macros v5.01, with the extension package ' $\mathrm{AGU}^{++}$' by P. W. Daly, version $1.6 \mathrm{~b}$ from 1999/08/19. 